\title{
Modeling the phase behaviour of bitumen/n-alkane systems with the cubic plus association (CPA) equation of state
}

\author{
Zhang, Yechun; Arya, Alay; Kontogeorgis, Georgios; Yarranton, Harvey
}

\section{Published in:}

Fluid Phase Equilibria

Link to article, DOI:

10.1016/j.fluid.2019.01.004

Publication date:

2019

Document Version

Peer reviewed version

Link back to DTU Orbit

Citation (APA):

Zhang, Y., Arya, A., Kontogeorgis, G., \& Yarranton, H. (2019). Modeling the phase behaviour of bitumen/nalkane systems with the cubic plus association (CPA) equation of state. Fluid Phase Equilibria, 486, 119-138. https://doi.org/10.1016/j.fluid.2019.01.004

\section{General rights}

Copyright and moral rights for the publications made accessible in the public portal are retained by the authors and/or other copyright owners and it is a condition of accessing publications that users recognise and abide by the legal requirements associated with these rights.

- Users may download and print one copy of any publication from the public portal for the purpose of private study or research.

- You may not further distribute the material or use it for any profit-making activity or commercial gain

- You may freely distribute the URL identifying the publication in the public portal 


\title{
Modeling the Phase Behaviour of Bitumen/n-Alkane Systems with the Cubic Plus Association (CPA) Equation of State
}

\author{
Yechun Zhang1, Alay Arya ${ }^{2}$, Georgios Kontogeorgis ${ }^{2}$, Harvey Yarranton ${ }^{1 *}$
}

1. Department of Chemical and Petroleum Engineering, University of Calgary, Canada

2. Center for Energy Resources Engineering, Technical University of Denmark, Denmark

* corresponding author: hyarrant@ucalgary.ca

\begin{abstract}
The cubic-plus-association equation of state was applied to model the phase behaviour of bitumen/n-alkane systems including saturation pressures, liquid-liquid boundaries, yields, and phase compositions. Yield is defined here as the mass of bitumen in the heavy phase divided by the mass of bitumen in the feed. To implement the model, the bitumen was divided into a set of pseudo-components based on a distillation assay and either the $n$-pentane insoluble content of the oil (CPA-C5 approach) or the propane insoluble content (CPA-C3 approach). The pseudocomponents in the solvent insoluble part of the oil were defined as self-associating components, all other pseudo-components were non-associating. The critical properties and acentric factor for each pseudo-component were determined from established correlations. A set of CPA parameters was then developed to fit the available phase behavior data. The self-associating pseudocomponents were assigned a distribution of self-association energies in order to capture the sequential partitioning of asphaltenes to the heavy phase upon solvent addition or in different solvents.

Both approaches matched the phase behavior data for mixtures of bitumen with n-pentane and higher carbon number $n$-alkanes almost to within the experimental error. The CPA-C3 approach also matched the phase behavior data for mixtures of propane and bitumen. The CPA-C5 approach could not match the yield data for propane diluted bitumen but was more straightforward to implement and was less computationally intensive because it employed fewer self-associating components. To apply either approach to another oil, only the self-association energy of the selfassociating pseudo-components need be adjusted. The cross-association energy between the solvent and the self-associating pseudo-components must be tuned for any new solvent.
\end{abstract}

Keywords: phase behavior, bitumen, $n$-alkane, cubic plus association equation of state, phase boundaries, asphaltene yield, phase compositions 


\section{Introduction}

Phase behavior models for mixtures of bitumens (or heavy oils) and $n$-alkanes are required for the simulation of solvent-assisted in situ heavy oil recovery processes, solvent based oil sand extraction processes, and solvent deasphalting processes [1, 2]. These mixtures can form multiple phases including vapor-liquid (VL), liquid-liquid (LL), VLL, and possibly VLLL regions [3-6]. Depending on the solvent and the conditions, the second liquid phase can be a light solvent-rich phase or a heavy asphaltene-rich phase. Asphaltene-rich phase formation, often termed precipitation, and subsequent deposition is also a flow assurance issue for some conventional oil applications including undersaturated live oil depressurization and carbon dioxide flooding [7-10]. It has proven challenging to model the full range of crude oil/solvent phase behavior, particularly asphaltene-rich phase formation, with a single model and a consistent fluid characterization.

Asphaltenes are defined as the fraction of a crude oil that is insoluble in a paraffinic solvent (usually $n$-pentane or $n$-heptane) and soluble in an aromatic solvent (usually toluene). They are the heaviest and most aromatic fraction of a crude oil with the highest density, molecular weight and heteroatom content [11-13]. Asphaltenes are known to self-associate into nano-aggregates consisting of 5 to 10 molecules on average [14-16]. The changes in this self-association at different temperature, pressures, and compositions and the effect of self-association on crude oil phase behavior are currently ill-defined. Most crude oil phase behavior modeling approaches do not explicitly consider asphaltene self-association.

To facilitate the discussion of the modeling approaches, the following terms are defined:

- "onset": the condition (temperature, pressure, and composition) at which asphaltene precipitation first occurs. In this study, the onset is usually defined in terms of the precipitate content.

- “yield”: the amount of asphaltene precipitation (mass of precipitate divided by mass of oil).

To date, the two most successful approaches for modeling asphaltene precipitation are regular solution models and equations of state (EoS). Regular solution models are particularly useful in matching the onset and yield of precipitated asphaltenes from oils diluted with different solvents or in blends [17-20]. However, these models are limited to liquid-liquid or liquid-solid equilibria. 
Equations of state, on the other hand, can describe both vapor-liquid and liquid-liquid equilibria. They have been widely applied in the petroleum industry and are the cornerstone of modern chemical process simulators [21, 22].

Cubic equations of state (CEoS) are particularly popular due to their simplicity and relatively good accuracy in predicting vapour-liquid equilibrium and liquid-liquid equilibrium for small, non-polar, non-associating molecules, such as light hydrocarbons. CEoS can match the phase boundaries (L/LL and L/VL) for heavy oil mixed with paraffinic solvents and dissolved gases such as carbon dioxide [4,7]. However, they are unable to match the yield or composition of asphaltene-rich phases without the use of composition dependent binary interaction parameters [2,33]. CEoS cannot account for self-association and this lack may limit their ability to model asphaltene related phase behaviour.

Two equations of state (EoS) that account for molecular self-association are statistical association fluid theory (SAFT) [23] and cubic plus association (CPA) [24]. A modified version of SAFT was used to model the onset of asphaltene precipitation from a crude oil after $\mathrm{CO}_{2}$ and $\mathrm{CH}_{4}$ injection [8,9] and the yield of precipitated asphaltenes as a function of the gas-to-oil ratio [25]. The Perturbed Chain form of the SAFT (PC-SAFT) was used to match the yield of asphaltene precipitation from $n$-alkane diluted bitumens [10]. The self-association term within the SAFT model was not required or used in these studies. Similarly, CPA was used to model the onset of asphaltene precipitation during the depressurization of live oils with and without gas injection [2630], and the onset and yield for $n$-alkane diluted bitumens [31]. The asphaltene self-association term of the CPA was used in these studies and was tuned to match onset and yields. While both SAFT and CPA have shown promising results, this study focuses on the CPA approach because it could be constructed started from a previously developed oil characterization for a cubic equation of state [22, 39].

Although the CPA-EoS has been used to match asphaltene yield for different $n$-alkane diluted bitumen, the following issues with the oil characterization and modeling have yet to be addressed:

- The self-associating components are arbitrarily defined as the pentane insoluble fraction of the oil, "C5-asphaltenes”. This approach works well when the maximum yield is less than 
or equal to the C5-asphaltene content; for example when the bitumen is diluted with $n$ pentane or a higher carbon number $n$-alkane. However, the current approach is not equipped to match yield data when other components also precipitate; for example, when bitumen is diluted with propane or butane [3,33].

- Experimental data has shown that the heaviest, highest molecular weight asphaltenes precipitate first; that is, the material that precipitates at low $n$-alkane content consists predominantly of these heavier, more self-associated asphaltenes. The lighter asphaltenes only precipitate at higher $n$-alkane content [32]. The current approach predicts that all of the asphaltene fractions partition equally between the phases at all yields. This error could lead to incorrect phase behavior and property predictions for oil fractions; for example, for partially deasphalted oils.

- The ability of the model to predict phase compositions has not been tested.

- The CPA-EoS has been applied to SARA or GC based oil characterizations but not yet to distillation assay based characterizations. Distillation based characterizations are commonly used for refinery and other oil processing applications.

The objective of this study was to develop a methodology to model the phase behavior of diluted bitumens with the Cubic Plus Association equation of state and to evaluate the strengths and weakeness of this modeling approach. The methodology was developed by fitting the model to propane and $n$-pentane diluted bitumen phase boundaries, asphaltene precipitation data, and phase composition data from the literature at temperatures and pressures up to $150^{\circ} \mathrm{C}$ and $10 \mathrm{MPa}$, respectively $[2,33]$. The bitumen characterization was based on a distillation assay rather than a SARA or GC assay because boiling points are more representative of the molecular interactions that define the phase behaviour of the system [22]. The asphaltene fraction was characterized such that its highest boiling point cuts were less soluble than its lower boiling point cuts. Two different characterization approaches were proposed, CPA-C5 and CPA-C3, where "C5" and "C3" denote the material insoluble in $n$-pentane and propane, respectively; that is, asphaltenes. The CPA-C5 approach is similar to previous characterizations [28]. The CPA-C3 approach was proposed because the CPA-C5 approach was unable to fit asphaltene yield data from propane diluted bitumen. Both models were further tested on asphaltene precipitation data from the literature [34] for other bitumens diluted with precipitants such as $n$-pentane, $n$-hexane and $n$-octane at 
temperatures from 0 to $50^{\circ} \mathrm{C}$ at atmospheric pressure. The ability of the proposed approaches to predict other thermodynamic derivative properties was beyond the scope of this study and was not evaluated.

\section{Datasets}

\section{Dataset 1}

This dataset was used to develop a methodology to model the phase behaviour of bitumen/solvent pseudo-binaries with the CPA-EoS. This dataset contains saturation pressures (liquid/vapourliquid boundaries), onsets of asphaltene precipitation (liquid/liquid-liquid boundaries), yields, and phase compositions of pseudo-binaries WC-B-B2/n-pentane, WC-B-B3/propane and WC-BB4/propane. WC-B-B2, WC-B-B3, and WC-B-B4 are three Western Canada bitumen samples recovered from the same reservoir but with slightly different density, viscosity, and C5-asphaltene content, Table 1. Data for pseudo-binary WC-B-B2/n-pentane is reported at temperatures from 20 to $130^{\circ} \mathrm{C}$ at pressures up to $10 \mathrm{MPa}$ [2]. Data for pseudo-binaries WC-B-B3/propane and WC-B$\mathrm{B} 4 /$ propane are reported at temperatures from 20 to $130^{\circ} \mathrm{C}$ at pressures up to $10 \mathrm{MPa}$ [33]. A distillation assay was reported for the WC-B-B2 bitumen and is provided in Table 2. The distillation assay of the three bitumen samples was assumed to be the identical since the samples were obtained from the same source reservoir.

\section{Dataset 2}

This dataset was used to test the proposed methodology to model phase boundaries using the CPAEoS on independently measured data. It includes saturation pressures (liquid/vapor-liquid and liquid-liquid/vapor-liquid-liquid boundaries) of a Peace River bitumen/propane pseudo-binary reported at temperatures from 30 to $120^{\circ} \mathrm{C}$ and propane contents from 9.8 to $85.7 \mathrm{wt} \%$ [3]. Peace River bitumen is a Western Canada bitumen with similar physical properties to those of samples WC-B-B2, WC-B-B3, and WC-B-B4. The distillation assay of the Peace River bitumen was not reported and was assumed to be identical to that of the WC-B-B2 bitumen reported in Table 2. 
Table 1. Specific gravities and SARA assays for the bitumen samples in the Dataset 1 [2,33]. All three samples are from the same reservoir. The bitumen sample from Dataset 2 has the same properties as the WC-B-B2 bitumen.

\begin{tabular}{lccc}
\hline Property & WC-B-B2 & WC-B-B3 & WC-B-B4 \\
\hline Specific Gravity & 1.015 & 1.020 & 1.023 \\
Saturates, wt\% & 17.0 & - & - \\
Aromatics, wt\% & 46.9 & - & - \\
Resins, wt\% & 16.7 & - & - \\
C5-asphaltenes, wt\% & 19.4 & 19.2 & 22.3 \\
\hline
\end{tabular}

Table 2. Spinning band distillation assay of WC-B-B2 bitumen [2].

\begin{tabular}{cc}
\hline $\begin{array}{c}\text { Volume } \% \\
\text { Distilled }\end{array}$ & $\begin{array}{c}\text { Normal Boiling Point } \\
{ }^{\circ} \mathrm{C}\end{array}$ \\
\hline 1.7 & 218.0 \\
3.4 & 237.4 \\
5.0 & 252.4 \\
6.7 & 267.9 \\
8.4 & 278.6 \\
10.1 & 289.4 \\
11.8 & 301.7 \\
13.4 & 313.5 \\
15.1 & 324.0 \\
18.5 & 339.8 \\
20.2 & 349.6 \\
21.8 & 358.0 \\
23.5 & 367.3 \\
25.2 & 375.2 \\
26.9 & 380.0 \\
28.57 & 382.5 \\
30.25 & 384 \\
31.93 & 385 \\
\hline
\end{tabular}

\section{$\underline{\text { Dataset } 3}$}

This dataset was used to extend the CPA-EoS based methodology to model asphaltene precipitation for different $n$-paraffin diluted oils. It contains asphaltene precipitation data reported for three Western Canada bitumens (Athabasca, Lloydminster and Cold Lake) diluted with with 
$n$-paraffins ranging from $n$-pentane to $n$-octane, and for a Venezuelan heavy oil (Venezuela-1) diluted with $n$-pentane and $n$-heptane. The data is reported at temperatures from 0 to $23^{\circ} \mathrm{C}$ all at atmospheric pressure [34]. No distillation data were available for these oils and therefore the distillation assay of bitumen WC-B-B2 from Dataset 1 was used with only an adjustment to the measured asphaltene content. Selected physical properties and SARA assay of the oils in this dataset are presented in Table 3.

Table 3. Specific gravities and SARA assays for the bitumens in Dataset 3 [34].

\begin{tabular}{lcccc}
\hline Property & Athabasca & Cold Lake & Lloydminster & Venezuela-1 \\
\hline Specific Gravity & 1.022 & 1.007 & 1.001 & 1.023 \\
Saturates, wt\% & 16.3 & 19.4 & 23.1 & 15.4 \\
Aromatics, wt\% & 39.8 & 38.1 & 41.7 & 44.4 \\
Resins, wt\% & 28.5 & 26.7 & 19.5 & 25.0 \\
C5-asphaltenes, wt\% & 15.4 & 15.8 & 15.7 & 15.0 \\
\hline
\end{tabular}

\section{The CPA Equation of State}

The version of CPA used in this study was proposed by Kontogeorgis et al. [24] and combines the physical terms from the Soave-Redlich-Kwong (SRK) EoS with the association term derived by Michelsen and Hendriks [35] as follows:

$$
P=\frac{R T}{V_{m}-b}-\frac{a}{V_{m}\left(V_{m}+b\right)}-\frac{1}{2} \frac{R T}{V_{m}}\left(1+\rho \frac{\partial \ln g}{\partial \rho}\right) \sum_{i} x_{i} \sum_{A_{i}}\left(1-X_{A_{i}}\right)
$$

where $P$ is pressure, $R$ is the universal gas constant, $T$ is the temperature, $V_{m}$ is the molar volume, $a$ and $b$ are constants, $\rho$ is molar density, $g$ is the radial distribution function, $x_{i}$ is the mole fraction of component $i$, subscript $A$ denotes a type of site on the molecules in component $i$, and $X_{A i}$ is the fraction of Site $A$ in Component $i$ that is not bonded to other sites.

The radial distribution function, $g$, is given by:

$$
g=\frac{1}{1-1.9 b \rho / 4}
$$

For pure components and pseudo-components, the constants $a$ and $b$ are calculated as:

$$
a=0.42747 \frac{R^{2} T_{C}^{2}}{P_{c}}\left[1+c\left(1-\sqrt{\frac{T}{T c}}\right)\right]^{2}
$$




$$
b=0.08664 \frac{R T_{C}}{P_{c}}
$$

where

$$
c=0.48508+1.55171 \omega-0.15613 \omega^{2}
$$

and $T_{\mathrm{c}}, P_{\mathrm{c}}$ and $\omega$ are the critical temperature, critical pressure and acentric factor, respectively.

Parameters $a$ and $b$ for mixtures are calculated from those of the pure components or pseudocomponents using the classic van der Waals mixing rules:

$$
\begin{gathered}
a=\sum_{i} \sum_{j} x_{i} x_{j} \sqrt{a_{i} a_{j}}\left(1-k_{i j}\right) \\
b=\sum_{i} \sum_{j} x_{i} x_{j} b_{i j}, b_{i j}=\frac{1}{2}\left(b_{i}+b_{j}\right)
\end{gathered}
$$

For the association term (the last term in Eq. 1), each component must be classified into an association type with a specified number of association sites per molecule (up to 4). The sites must be defined as either positive representing proton donors, or negative representing proton accepters. By default, only sites with an opposite sign can associate with each other. The fraction of unoccupied sites, $X_{A i}$, is then related (analogously to the Langmuir adsorption isotherm) to the association strength $\Delta^{A_{i} B_{j}}$ between two sites (Site $A$ and $B$ ) on two different molecules ( $i$ and $j$ ) as follows:

$$
X_{A_{i}}=\frac{1}{1+\rho \sum_{j} x_{j} \sum_{B_{j}} X_{B_{j}} \Delta^{A_{i} B_{j}}}
$$

When $i \neq j$, the interaction is termed cross-association and when $i=j$, the interaction represents selfassociation. The self-association strength $\Delta^{A_{i} B_{i}}$ can be expressed as follows:

$$
\Delta^{A_{i} B_{i}}=g\left[\exp \left(\frac{\varepsilon^{A_{i} B_{i}}}{R T}\right)-1\right] b_{i i} \beta^{A_{i} B_{i}}
$$

where $\varepsilon^{A_{i} B_{i}}$ is the association energy and $\beta^{A_{i} B_{i}}$ is the association volume. In this study, the selfassociation and cross-association energies were adjusted manually or calculated from the selfassociation terms using the Elliot mixing rule given by:

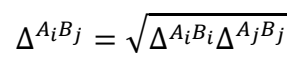

The association energy and volume are the two defining parameters for the association term in the CPA-EoS; that is, all of the interaction terms can be determined from the $\varepsilon^{A_{i} B_{i}}$ and $\beta^{A_{i} B_{i}}$ of the components and pseudo-components. Hence, once the number and type of association sites for the associating components has been defined, the CPA-EoS requires a total of 5 parameters for each 
component: $T_{\mathrm{c}}, P_{\mathrm{c}}$, and $\omega$ for the SRK physical terms, and, $\varepsilon^{A_{i} B_{i}}$ and $\beta^{A_{i} B_{i}}$ for the association term. Binary interaction parameters in Eq. 6 must also be defined for each pair of components or pseudocomponents.

\section{Modeling Methodology}

Like all equations of state, the modeling methodology involves representing the oil as a set of pseudo-components with defined properties (oil characterization), performing a flash calculation, and then tuning some model parameters to fit the available data. The key step in this work is the oil characterization which includes assigning the critical properties and acentric factor for each pseudo-component, defining the association type and number of association sites per pseudocomponent molecule, assigning the CPA volume and energy parameters, and setting binary interaction parameters.

The "trick" to modeling asphaltene precipitation with the CPA-EoS is to recognize that the components that primarily form a heavy phase and contribute to the maximum yield (the yield at high precipitant contents) are the self-associating components within the characterization. The self-association was necessary to partition components preferentially to the heavy phase even at high solvent contents in the feed. In other words, the self-association counters the effect of dilution something a cubic EOS cannot model accurately without the use of composition dependent binary interaction parameters [39]. The CPA-EoS can be tuned to accurately predict yields below the input amount of self-associating components but not above. Therefore, the amount of selfassociating components must be defined to equal or exceed the maximum yield to be modeled. The problem is that the maximum yield is different for different solvents. One solution is to define the amount of self-associating components based on the highest yield expected to be encountered in any application. For solvent diluted bitumens, that amount is the "asphaltene" yield in propane diluted bitumen (C3-asphaltenes). Note that the C3-asphaltenes include many components that would typically be defined as resins or maltenes.

Two characterization were prepared: 1) a "traditional" characterization with the amount of selfassociating components based on the C5-asphaltene content; 2) a modified characterization based on the C3-asphaltene (propane insoluble) content. The CPA model with the two characterizations 
are denoted as the "CPA-C5" and "CPA-C3" approaches. The CPA-C5 approach is simpler but is incapable of predicting C3-asphaltene yields for propane diluted bitumen. The CPA-C3 approach addresses this deficiency. The two characterizations are presented in detail below. Then the changes made to the characterizations for other oils and solvents are discussed. Finally, the flash calculation procedure is described.

\subsection{Oil Characterization: Pseudo-Components (Dataset 1)}

The WC-B-B3 bitumen from Dataset 1 was characterized based on distillation assay data based on a characterization procedure presented in detail elsewhere [2, 33]. Briefly, the maltenes and asphaltenes were characterized separately. The maltene fraction was divided into a set of pseudocomponents with critical properties, acentric factors and molecular weights calculated from the Lee-Kesler correlations [36]. The maltene pseudo-component specific gravities, used as inputs for the Lee-Kesler correlations, were calculated from the Katz-Firoozabadi correlation [37]. In this study, the asphaltenes were represented as self-associating components instead of nano-aggregates with a fixed molecular weight distribution as is done in other models [2,7-11,19,20,33,34]. Hence, only the asphaltene monomer properties were defined. The asphaltene monomer molecular weight was set to $800 \mathrm{~g} / \mathrm{mol}[12,16,38]$ and the monomer critical properties and acentric factor were obtained from Arya et al. [27, 28].

The asphaltene pseudo-components were set to have four association sites per molecule. Two sites are set as negative and two as positive. These sites can bond with sites on the same species (selfassociation) or with other species (cross-association). The maltenes and the $n$-alkane solvent were set to have 1 site per molecule, which can cross-associate with either the positive or negative sites of the asphaltene pseudo-components. These sites cannot self-associate and can only interact with sites on other molecules through defined cross-association energies; in this study, they can only interact with the asphaltenes.

The CPA-C5 and CPA-C3 approaches differed in the mass and number of pseudo-components assigned to the self-associating and non-associating components. In the CPA-C5 characterization, the amount of self-associating material was set to the mass fraction of C5-asphaltenes in the bitumens from Dataset 1, Table 1. The maltenes were divided into 10 pseudo-components, each 
representing a mass fraction interval of the same width. The asphaltenes were similarly divided into 6 pseudo-components. Selected physical properties of the WC-B-B3 bitumen maltene and asphaltene pseudo-components are shown in Table 4. This characterization can be used for mixtures of bitumen and $n$-alkanes of carbon number 5 or more.

In the CPA-C3 approach, the CPA-C5 characterization was modified to model the phase behavior of bitumen diluted with propane as well as higher carbon number $n$-alkanes. The asphaltene content was redefined to the measured propane insoluble asphaltene content of the WC-B-B3 bitumen; in other words, $49.2 \mathrm{wt} \%$ of the oil was defined as self-associating components. This value was the minimum content of self-associating components necessary to fit the yield data and is equivalent to the minimum measured yield at high dilution with propane (see Figure 5). The maltenes and asphaltenes were divided into 6 and 10 pseudo-components, respectively, with the properties shown in Table 5.

Table 4. Number of association sites and properties of the WC-B-B3 bitumen pseudo-components for the CPA-C5 characterization.

\begin{tabular}{ccccccc}
\hline Component & $\begin{array}{c}\text { Number of } \\
\text { Association } \\
\text { Sites* }\end{array}$ & $\begin{array}{c}\text { Mass } \\
\text { Fraction }\end{array}$ & $\begin{array}{c}\text { Tc } \\
\mathrm{K}\end{array}$ & $\begin{array}{c}\mathrm{Pc} \\
\mathrm{kPa}\end{array}$ & $\begin{array}{c}\text { Acentric } \\
\text { Factor }\end{array}$ & $\begin{array}{c}\mathrm{MW} \\
\mathrm{g} / \mathrm{mol}\end{array}$ \\
\hline Maltene 1 & 1 & 0.0808 & 738 & 2440 & 0.753 & 299 \\
Maltene 2 & 1 & 0.0808 & 790 & 2079 & 0.836 & 368 \\
Maltene 3 & 1 & 0.0808 & 829 & 1844 & 0.919 & 429 \\
Maltene 4 & 1 & 0.0808 & 859 & 1690 & 1.002 & 480 \\
Maltene 5 & 1 & 0.0808 & 883 & 1581 & 1.085 & 523 \\
Maltene 6 & 1 & 0.0808 & 904 & 1489 & 1.168 & 561 \\
Maltene 7 & 1 & 0.0808 & 923 & 1382 & 1.251 & 599 \\
Maltene 8 & 1 & 0.0808 & 946 & 1281 & 1.334 & 644 \\
Maltene 9 & 1 & 0.0808 & 973 & 1150 & 1.417 & 706 \\
Maltene 10 & 1 & 0.0808 & 1008 & 1006 & 1.500 & 795 \\
Asphaltene 1-6 & 4 & 0.032 & 1008 & 1186 & 1.535 & 800 \\
\hline me pseudo-components have one association site that can cross-associate with both positive and negative sites
\end{tabular}

*Maltene pseudo-components have one association site that can cross-associate with both positive and
of an asphaltene molecule. Asphaltenes have 4 association sites: 2 positive sites and 2 negative sites. 
Table 5. Number of association sites and properties of the WC-B-B3 bitumen pseudo-components for the CPA-C3 characterization.

\begin{tabular}{lcccccc}
\hline Component & $\begin{array}{c}\text { Number of } \\
\text { Association } \\
\text { Sites* }\end{array}$ & $\begin{array}{c}\text { Mass } \\
\text { Fraction }\end{array}$ & $\begin{array}{c}\text { Tc } \\
\text { K }\end{array}$ & $\begin{array}{c}\text { Pc } \\
\mathrm{kPa}\end{array}$ & $\begin{array}{c}\text { Acentric } \\
\text { Factor }\end{array}$ & $\begin{array}{c}\mathrm{MW} \\
\mathrm{g} / \mathrm{mol}\end{array}$ \\
\hline Maltene 1 & 1 & 0.0833 & 738 & 2440 & 0.753 & 299 \\
Maltene 2 & 1 & 0.0833 & 790 & 2079 & 0.836 & 368 \\
Maltene 3 & 1 & 0.0833 & 829 & 1844 & 0.919 & 429 \\
Maltene 4 & 1 & 0.0833 & 859 & 1690 & 1.002 & 480 \\
Maltene 5 & 1 & 0.0833 & 883 & 1581 & 1.085 & 523 \\
Maltene 6 & 1 & 0.0833 & 904 & 1489 & 1.168 & 561 \\
Asphaltene 1-10 & 4 & 0.050 & 1008 & 1186 & 1.535 & 800 \\
\hline
\end{tabular}

*Maltene pseudo-components have one association site that can cross-associate with both positive and negative sites of an asphaltene molecule. Asphaltenes have 4 association sites: 2 positive sites and 2 negative sites.

\subsection{Oil Characterization: Binary Interaction and CPA Parameters}

The binary interaction parameters and the CPA self-association volume and energy parameters were used to tune the model primarily based on Dataset 1 . In general, the tuning was more extensive for the CPA-C3 versus the CPA-C5 approach because it included more self-associating components and was able to match more data. The rationale behind the tuning is discussed below and the complete set of tuned parameters is provided in Appendix A.

\section{$\underline{\text { Binary Interaction Parameters }}$}

The binary interaction parameters in Eq. 6 were found to depend both on the characterization approach and on the type of solvent. To begin with, all of the binary interaction parameters $\left(k_{\mathrm{ij}}\right)$ were set to zero except for those of solvent/maltene pseudo-binaries. These binary interaction parameters were estimated by fitting the CPA-EoS to experimental saturation pressures. The solvent/maltene binary interaction parameters for $n$-pentane and propane diluted bitumen are provided in Table 6 and discussed below. 
Table 6. The tuned binary interaction parameters for the bitumen in Dataset 1.

\begin{tabular}{lcc}
\hline Parameter & CPA-C5 & CPA-C3 \\
\hline$k_{\text {Malt } / \text { C5 }}$ & $\mathrm{T} \leq 1.0427 \mathrm{~T}_{\mathrm{C}, \mathrm{C} 5}:-0.03$ & $\mathrm{~T} \leq 1.0277 \mathrm{~T}_{\mathrm{C}, \mathrm{C} 5}:-0.03$ \\
& $\mathrm{~T}>1.0427 \mathrm{~T}_{\mathrm{C}, \mathrm{C5}:}: 1.144-1.126\left(\frac{T}{T_{c, C 5}}\right)$ & $\mathrm{T}>1.0277 \mathrm{~T}_{\mathrm{C}, \mathrm{C5}}: 1.903-1.881\left(\frac{T}{T_{c, C 5}}\right)$ \\
$k_{\text {Malt } / \text { 3 } 3}$ & -0.057 & -0.11 \\
$k_{\text {Asph/C3 }}$ & - & -0.026 \\
All others & 0 & 0 \\
\hline
\end{tabular}

n-Pentane Diluted Bitumen: For both the CPA-C5 and CPA-C3 approaches, the binary interaction parameters of the maltene/ $n$-pentane pseudo-binaries were found to be constant $\left(k_{\mathrm{Malt} / \mathrm{C5}}=-0.03\right)$ below the critical temperature of $n$-pentane $\left(T_{c, C 5}=469.7 \mathrm{~K}\right)$. It was necessary to add a temperature dependence above this critical temperature, as shown in Table 6, with a slightly different temperature dependence for each approach. The correlations are based on data from 20 to $280^{\circ} \mathrm{C}$ and may not be valid at higher temperatures.

Propane Diluted Bitumen: For both the CPA-C5 and CPA-C3 approaches, the binary interaction parameters of the maltene/propane pseudo-binaries were found to be constant but with different values for each approach $\left(k_{\text {Malt } / \text { C3 }}=-0.057\right.$ for CPA-C5 and -0.11 for CPA-C3). Note, there were few data points above the critical temperature of propane $\left(T_{c, C 3}=369.8 \mathrm{~K}\right)$ and it is possible the interaction parameter would require adjustment at higher temperatures. In addition, for the CPAC3 approach, a non-zero interaction parameter was added for all of the asphaltene/propane pseudobinaries $\left(k_{A s p h / C 3}=-0.026\right)$ in order to fit the asphaltene yield data.

\section{CPA Association Volume Parameters}

The CPA association volume parameters are provided in Table 7. For both approaches, the selfassociation volume parameter was set to 0.05 for all asphaltene pseudo-components. The selfassociation volume parameters for the maltenes and solvents were all set to zero because they do not self-associate. The cross-association volume parameters for asphaltene/asphaltene, asphaltene/maltene, and asphaltene/solvent pseudo-pairs were all set to 0.05 as recommended by Arya et al. [28]. 
Table 7. The CPA volume parameters for mixtures of oil and solvent (same for both CPA-C3 and CPA-C5 approaches); X indicates any component.

\begin{tabular}{lc}
\hline Component Pair & Volume Parameter \\
\hline$\beta^{\text {Asph } X}$ & 0.05 \\
All others & 0 \\
\hline
\end{tabular}

\section{CPA Energy Parameters}

Recall that the CPA energy parameters include self-association energies, $\varepsilon^{A A}$, for each selfassociating component (asphaltenes) and cross-association energies, $\varepsilon^{A B}$, for each pair of crossassociating components (asphaltene/maltene, asphaltene/solvent and asphaltene/asphaltene pseudo-pairs). There is no cross-association between the maltene pseudo-component pairs or between the maltene pseudo-components and the solvent; hence their cross-association energies are zero. The cross-association energy of asphaltene/asphaltene pseudo-pairs, $\varepsilon^{A i A j}$, was calculated from the Elliot mixing rule (Eq. 10) using self-association strength calculated from Eq. 9. Therefore, there are three parameters remaining to be tuned: the self-association energy of asphaltene pseudo-components ( $\left.\varepsilon^{A i A i}\right)$, the cross-association energies of asphaltenes/maltenes ( $\varepsilon^{\text {AsphMalt }}$ ), and the cross-association of the asphaltenes/solvent pseudo-pairs ( $\varepsilon^{\text {AsphSolv }}$ and $\left.\varepsilon^{A i A j}\right)$. The asphaltene self-association parameters have a physical basis in the sense that the asphaltenes largely consist of self-associating components. The cross-association between maltenes and asphaltenes is consistent with previous CPA models which require cross-association between aromatic species and self-associating compounds such as water and glycols (Kontogeorgis and Folas, 2010). The cross-association between asphaltenes and solvents has no known physical basis and is simply used as a tuning parameter.

These three energy parameters were adjusted to fit the CPA-EoS to asphaltene precipitation data as described below. There is not a unique set of energy parameters that fit the data; hence, they were constrained within the physically reasonable range from $500 \mathrm{~K}$ to $7500 \mathrm{~K}$ as recommended by Arya et al. [28]. The parameters were optimized manually by setting the self-association parameter and optimizing the cross-association parameters. The optimization was repeated with different self-association parameters to reach an approximate global optimum. The optimization was relatively straightforward because the self-association parameter more strongly affected the

Kommenterede [HY2]: Georgios and Alay: please check this paragraph. 
yields while the cross-association more strongly affected the onsets. The tuned parameters are provided in Table 8 and discussed below.

Table 8. The tuned CPA energy parameters for the bitumen in Dataset 1 . See Figure 1 for details on the asphaltene/solvent cross association energies; $\mathrm{C} 3=$ propane and $\mathrm{C} 5+=n$-pentane and higher carbon number $n$-alkanes.

\begin{tabular}{lcc}
\hline Parameter & CPA-C5 & CPA-C3 \\
\hline$\left(\varepsilon^{\text {AiAi }} / R\right)^{\circ}$ in C3, K & 6840 & 6500 \\
$\left(\varepsilon^{\text {AiAi }} / R\right)^{\circ}$ in C5+, K & 6840 & 5950 \\
$\Delta\left(\varepsilon^{\text {AiAi } / R)^{\circ}, \mathrm{K}}\right.$ & 60 & 60 \\
$\varepsilon^{\text {AiAj } / R, \mathrm{~K}}$ & Elliot, Eq. 10 & Elliot, Eq. 10 \\
$\varepsilon^{\text {Asph/Malt } / R \text { in C3, K }}$ & $3241+2.325 \mathrm{~T}$ & $2765+3.055 \mathrm{~T}$ \\
$\varepsilon^{\text {Asph/Malt } / R \text { in C5+, K }}$ & $3241+2.325 \mathrm{~T}$ & $1985+5.543 \mathrm{~T}$ \\
$\varepsilon^{\text {Asph/Solv }} / R$ (min), $\mathrm{K}$ & 2580 & 2000 \\
$\varepsilon^{\text {Asph/Solv } / R \text { (max }), \mathrm{K}}$ & 3250 & 4000 \\
All others & 0 & 0 \\
\hline
\end{tabular}

Asphaltene Self-Association Energies: These energies were set primarily to match the shape of the asphaltene yield curve and to capture the sequential partitioning of asphaltenes to the heavy phase upon dilution with the given solvent. The reduced energies (energy divided by the gas constant, $R$ ) were set to a tunable value, $\left(\varepsilon^{A i A i} / R\right)^{\circ}$, in $\mathrm{K}$, for the first asphaltene pseudo-component and incremented by $60 \mathrm{~K}$ for each subsequent fraction. The value of $\left(\varepsilon^{A i A i} / R\right)^{\circ}$ can be tuned for each oil and, for the CPA-C5 approach, it was set to $6840 \mathrm{~K}$ for the WC-B-B2 bitumen.

Recall that the asphaltene fraction was divided into 10 pseudo-components in the CPA-C3 approach. In this case, a constant value, $\left(\varepsilon^{A i A i} / R\right)^{\circ}$, was set for the first 6 asphaltene pseudocomponents. This self-association energy was incremented by $60 \mathrm{~K}$ successively for each of the remaining 4 asphaltene pseudo-components. $\left(\varepsilon^{A i A i} / R\right)^{\circ}$ was set to $5950 \mathrm{~K}$ for the WC-B-B2 bitumen diluted with $n$-pentane and higher carbon number $n$-alkanes. It was necessary to adjust $\left(\varepsilon^{A i A i} / R\right)^{\circ}$ to $6500 \mathrm{~K}$ for WC-B-B2 bitumen diluted with propane, suggesting that asphaltenes self-associate more strongly in propane than in $n$-pentane. The value for $\left(\varepsilon^{A i A i} / R\right)^{\circ}$ is higher than the value found for the CPA-C5 asphaltene pseudo-components. 
Asphaltene/Maltene Cross-Association Energies: The reduced asphaltene/maltene cross association energies, $\varepsilon^{A s p h M a l t} / R$, were set primarily to match the onset of asphaltene precipitation at different temperatures (23 to $230^{\circ} \mathrm{C}$ for $n$-pentane and 20 to $90^{\circ} \mathrm{C}$ for propane). For each of the CPA-C5 and CPA-C3 approaches, the fitted parameters were correlated to temperature as shown in Table 8. For the CPA-C5 approach one correlation was sufficient for all solvents considered. For the CPA-C3 approach, one correlation was found for mixtures of bitumen and propane but another for mixtures of bitumen with $n$-pentane and higher $n$-alkane number solvents. There is no obvious physical basis for the use of different asphaltene/maltene cross-association energies in different solvents; hence, it appears that the model is not completely capturing the physical basis of the phase behavior. The necessity for this additional tuning is a weakness for the CPA-C3 characterization.

For bitumen/propane mixtures, the magnitude of the cross-association energy of asphaltene/maltene pseudo-binaries from the CPA-C3 approach is higher than that of asphaltene/maltene pseudo-binaries from the CPA-C5 approach from 20 to $90^{\circ} \mathrm{C}$. However, the predicted energies are higher than the CPA-C5 approach above $100^{\circ} \mathrm{C}$. There is no obvious explanation for this cross-over; hence, caution is advised if using the CPA-C3 approach for mixtures of bitumen and propane above $90^{\circ} \mathrm{C}$.

Asphaltene-Solvent Cross-Association Energies: This energy was the main parameter used to fit the maximum asphaltene yield in each $n$-alkane solvent using the data for diluted crude oils in Dataset 3. Essentially, reduced cross-association energies above a certain value (approximately $2600 \mathrm{~K}$ for CPA-C5 and $2000 \mathrm{~K}$ for CPA-C3) allowed a component to precipitate. The asphaltenesolvent cross-association energy was also set to decrease with increasing asphaltene pseudocomponent number as shown in Figure 1a for the CPA-C5 approach and Figure 1b for the CPAC3 approach. This modification ensured that all asphaltene pseudo-components precipitated in low carbon number $n$-alkanes, such as $n$-pentane, but only the most strongly associated pseudocomponents precipitated in higher carbon number $n$-alkanes. In effect, the cross-association energies tuned the solubility of each asphaltene component without compromising the match to 
the phase boundaries and yields. Such a tuning could not be achieved by adjusting the asphaltene self-association energies.

The shape of curves shown in Figure 1 were adjusted to ensure the correct order of precipitation for asphaltene pseudo-components in a given solvent. For the CPA-C5 approach, the minimum and maximum asphaltene/solvent reduced cross-association energies, $\varepsilon^{C 5 A s p h / S o l v} / R$ (in K), were set to 2580 and $3250 \mathrm{~K}$, respectively, for the solvents in this study. For the CPA-C3 approach, the minimum and maximum cross-association energies were set to $2000 \mathrm{~K}$ and $4000 \mathrm{~K}$, respectively. Values outside this range had a negligible effect on the CPA-EoS predictions and were not considered.
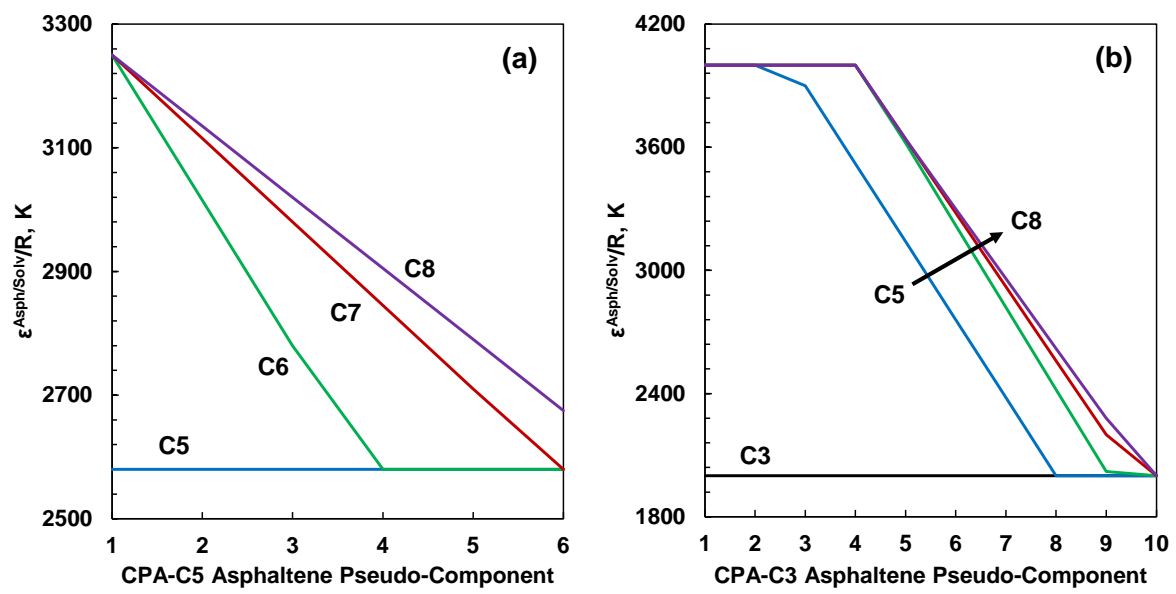

Figure 1. Tuned asphaltene-solvent reduced cross-association energy, $\varepsilon^{C 5 A s p h S o l v} / R$, for different $n$-paraffin solvents. The asphaltene pseudo-components were defined from: a) the CPA-C5 characterization approach; b) the CPA-C3 characterization approach.

\subsection{Tuning the Model for Other Oils and Solvents}

The asphaltene precipitation curves for the diluted bitumens in Dataset 3 were modelled using the CPA-EoS as follows. Both characterization approaches, CPA-C5 and CPA-C3, were tested. The critical properties and acentric factors for pseudo-components were estimated as described in Section 4.1. The CPA association volume parameters were used as introduced in Section 4.2. The 
asphaltene-solvent cross-association energies were used as shown in Figure 1a for the CPA-C5 approach and Figure 1b, for the CPA-C3 approach. They were not adjusted for the different oils. The model was tuned to match the onset condition for each oil in $n$-heptane at $23^{\circ} \mathrm{C}$ and atmospheric pressure by adjusting the base line self-association energy, $\left(\varepsilon^{A i A i} / R\right)^{\circ}$, of the asphaltene pseudo-components. The self-association energies for the higher fractions of the asphaltene pseudo-component were incremented as described previously. The tuned values for the Athabasca, Cold Lake, Lloydminster and Venezuela-1 bitumens are provided in Table 9. The $\left(\varepsilon^{A i A i} / R\right)^{\circ}$ parameter is the only tuning parameter required to match yield data from different bitumens at $23^{\circ} \mathrm{C}$. All other parameters were unchanged from the base case characterizations.

Table 9. The tuned $\left(\varepsilon^{A i A i} / R\right)^{\circ}$ in $\mathrm{K}$ for the oils in Dataset 3.

\begin{tabular}{lcc}
\hline Bitumen & $\left(\varepsilon^{\text {AiAi } / R)^{\circ}, \mathrm{K}}\right.$ \\
\hline Athabasca & 6840 & CPA-C3 \\
Cold Lake & 6860 & 6080 \\
Lloydminster & 6890 & 6100 \\
Venezuela-1 & 6850 & 6140 \\
\hline
\end{tabular}

\subsection{Flash Calculation}

The flash calculations were performed in Matlab 2017b using a multi-phase flash algorithm package developed by the Technical University of Denmark (DTU). The algorithm uses a standard Rachford-Rice algorithm that converge to a fugacity based phase equilibrium. In this work, the yield curves were generated by increasing the $n$-alkane content in feed in 1 wt\% steps and calculating the yield at each feed composition. The saturation pressures and liquid-liquid phase boundaries were determined with a linear search for the phase change with increasing pressure at different solvent contents in the feed mixture. Although this method is inefficient, it is the most reliable approach for identifying the phase boundaries.

For the CPA-C3 based characterization approach with 7 non-associating and 10 associating fractions in the mixture, 50 flash calculations per second were achieved with a $3.4 \mathrm{GHz}$ Intel Core 
i7 processor. For the CPA-C5 based characterization approach with 11 non-associating and 6 associating fractions in the mixture, 80 flash calculations per second were achieved.

\section{Results and Discussion}

First, the results for $n$-pentane diluted and propane diluted bitumen with CPA-C5 and CPA-C3 characterization approaches are discussed and compared. Then, the extension of the model to other bitumens and solvents is examined. Finally, the limiting number of pseudo-components is identified and the strengths and limitations of the proposed methodology are discussed.

\section{1 n-Pentane Diluted Bitumen}

Figure 2 shows the saturation pressures (L/VL boundaries) and onsets (L/LL boundaries) for the $n$-pentane diluted bitumen from Dataset 1 . The CPA-C5 approach (dashed lines) matched the saturation pressures to within the experimental error up to the critical point of of $n$-pentane $\left(197^{\circ} \mathrm{C}\right)$. At temperatures above this critical temperature, the model predicted a small VLL region and the measured pressures are consistent with the predicted LL/VLL boundary. The model slightly underpredicted the upper boundary of the VLL region at $280^{\circ} \mathrm{C}$. Recall that the CPA-EoS was tuned by adjusting $n$-pentane/maltene binary interaction parameters to match saturation pressures (see Section 4.2); however, tuning the CPA-EoS at temperatures higher than the critical temperature of the solvent was challenging and larger deviations between experimental and calculated saturation pressures were found. Note, the experimental errors for the saturation pressures were $\pm 0.1,0.3,0.4,0.55$ and $0.725 \mathrm{MPa}$ at temperatures of $90,140,180,230$, and $280^{\circ} \mathrm{C}$, respectively [2].

The CPA-C5 model also matched the onsets (L/LL boundaries) to within the experimental error, $\pm 1.5 \mathrm{wt} \%$ [2], with one exception. The model underpredicted the onset at $180^{\circ} \mathrm{C}$ and $5 \mathrm{MPa}$ although it matched the onset at $180^{\circ} \mathrm{C}$ and $10 \mathrm{MPa}$. The issue is likely a failure to predict the pressure dependence of the onsets at a fixed temperature, as will be discussed later for the propane diluted bitumen. 
Now consider the same $n$-pentane diluted bitumen discussed above but modelled using the CPA- C3 approach (Section 4.2). In general, the CPA-EoS with both characterization approaches, CPA-C5 and CPA-C3, has essentially the same performance in matching phase boundaries at temperatures below the critical temperature of $n$-pentane $\left(197^{\circ} \mathrm{C}\right)$, Figure 2 (solid lines). The most notable differences were found at temperatures above the critical temperature of $n$-pentane. At $230^{\circ} \mathrm{C}$, the CPA-C3 model predicts the intersection of the L/VL and LL/VLL boundaries at higher $n$-pentane content. In addition, The VLL region predicted by the CPA-C3 approach is larger than that predicted by the CPA-C5 approach with the CPA-C3 approach over-predicting the saturation pressures in this region. Note, neither CPA-C5 not CPA-C3 approaches were able to capture the effect of pressure on the onset of asphaltene precipitation at $180^{\circ} \mathrm{C}$, Figure $2 \mathrm{~d}$.

Figure 3 shows the yield curves for the $n$-pentane diluted bitumen from Dataset 1 at temperatures from 20 to $250^{\circ} \mathrm{C}$ and pressures up to $13.8 \mathrm{MPa}$. The CPA-C5 approach (dashed lines) fit the yield curves up to $180^{\circ} \mathrm{C}$ to within the experimental error, $\pm 1.5 \mathrm{wt} \%$, except at $140^{\circ} \mathrm{C}$ where the deviations reached $3 \mathrm{wt} \%$. The CPA-C3 model (solid lines) matched the yield data at all conditions to within the experimental error. Note that both the CPA-C5 and CPA-C3 approaches overpredicted the onset at $250^{\circ} \mathrm{C}$ by approximately $4 \mathrm{wt} \%$. As will be discussed later, neither approach can capture the effect of pressure on the onset.

Table 10 lists the measured and modeled phase compositions at feed $n$-pentane contents from 59 to $73 \mathrm{wt} \%$ at $180^{\circ} \mathrm{C}$ and $4.8 \mathrm{MPa}$ from Dataset 1 . No composition data were reported at temperatures above the critical point of $n$-pentane. The CPA-C5 model matched the measured compositions with an average absolute deviation of $2 \mathrm{wt} \%$ for the light phase and $5 \mathrm{wt} \%$ for the heavy phase. The CPA-C3 model performed slightly worse with an average absolute deviation of $2 \mathrm{wt} \%$ for the light phase and $7 \mathrm{wt} \%$ for the heavy phase. Both models consistently under-predicted the asphaltene content in the light phase and tended to under-predict the $n$-pentane content in the heavy phase. 

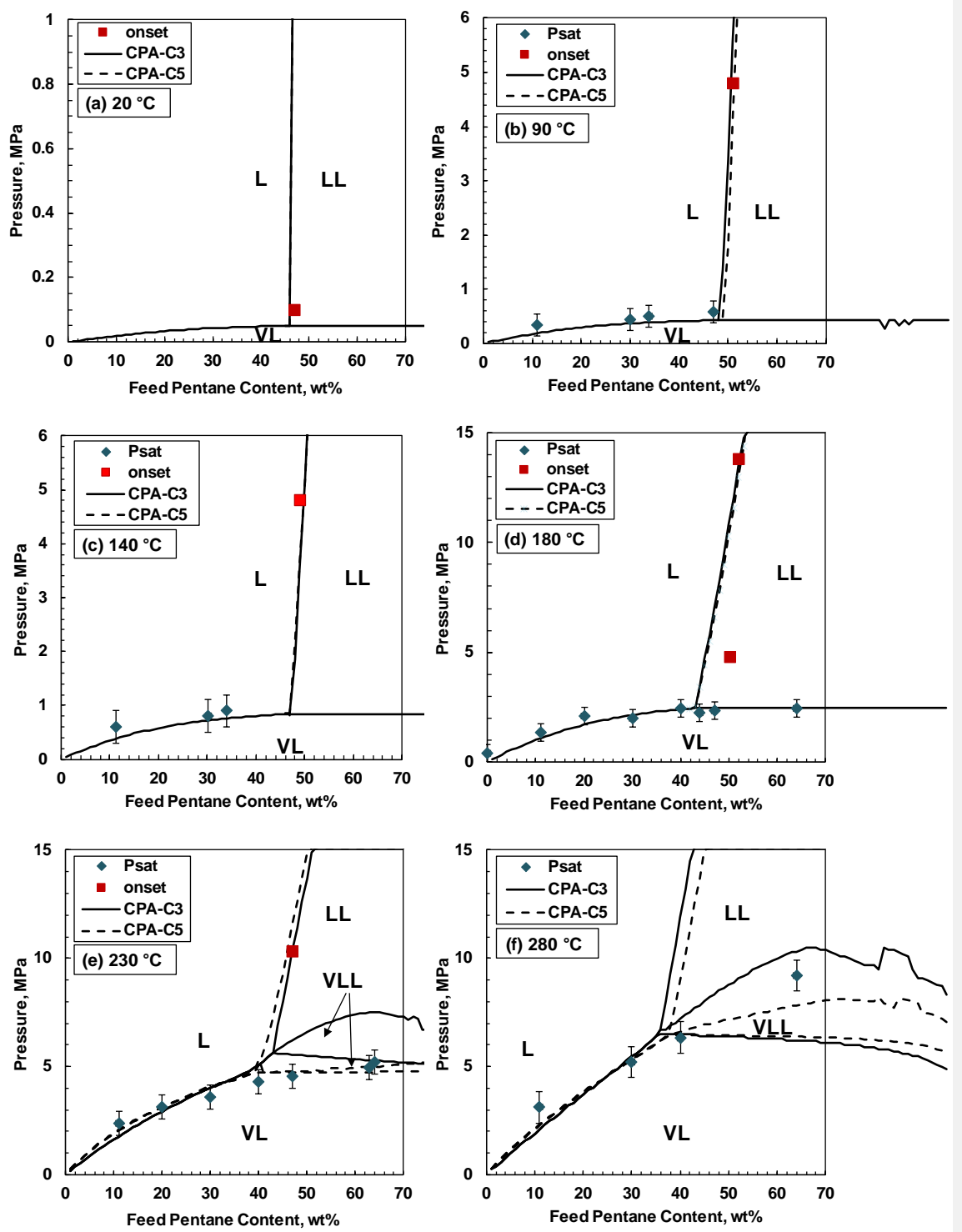

Figure 2. Pressure-composition diagram showing the saturation pressures and liquid-liquid boundaries (onset) for $n$-pentane diluted WC-B-B3 bitumen from Dataset 1 at: a) $20^{\circ} \mathrm{C}$; b) $90^{\circ} \mathrm{C}$; c) $140^{\circ} \mathrm{C}$; d) $180^{\circ} \mathrm{C}$; e) $230^{\circ} \mathrm{C}$; f) $280^{\circ} \mathrm{C}$. The onsets shown in (c) and (e) were measured at 120 and $250^{\circ} \mathrm{C}$, respectively. Symbols are data [2]; solid and dashed lines are the CPA-C3 and CPAC5 models, respectively. 

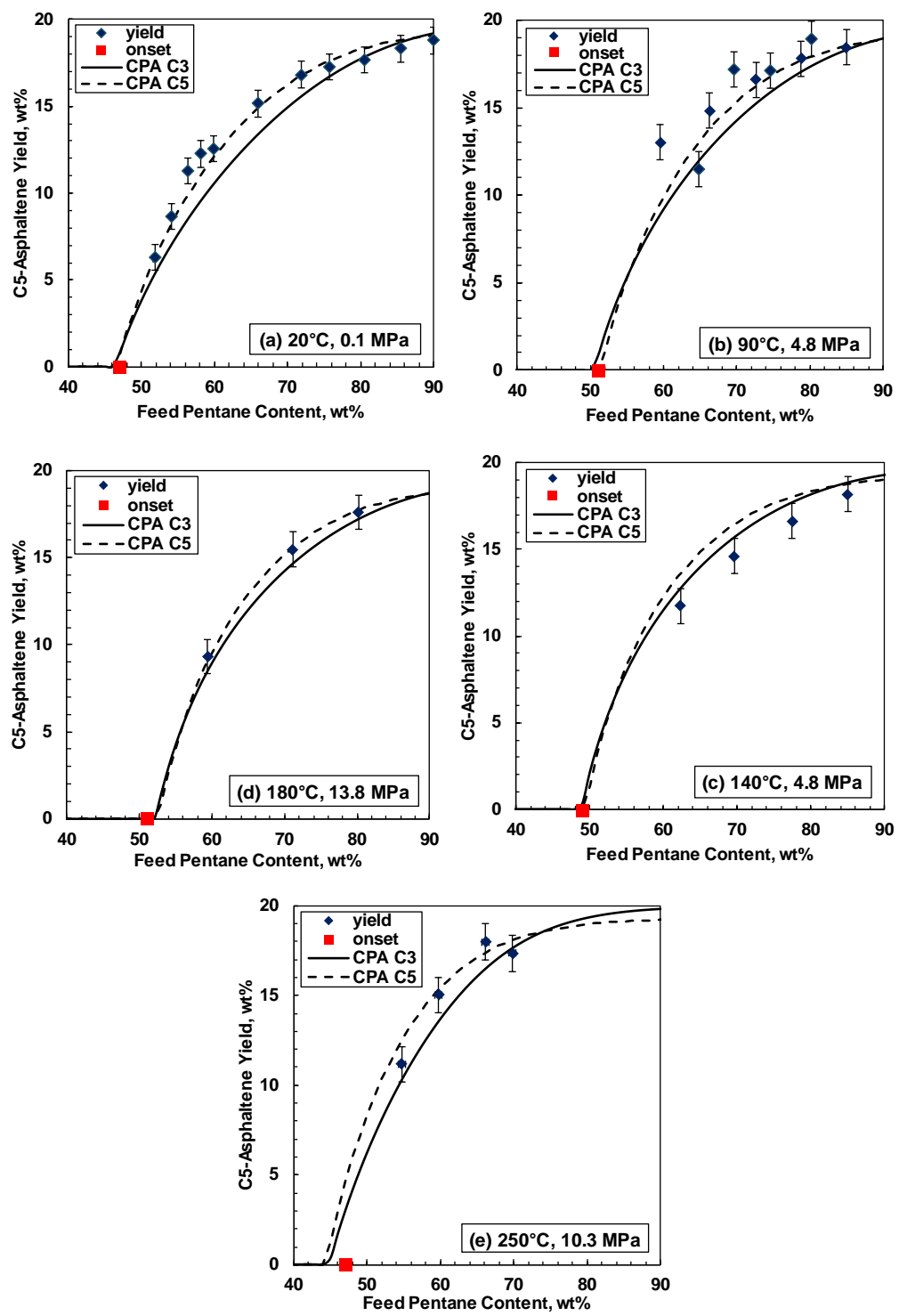

Figure 3. Measured and modeled C5-asphaltene yields from pentane diluted bitumen from Dataset 1 at: a) $20^{\circ} \mathrm{C}, 0.1 \mathrm{MPa}$; b) $90^{\circ} \mathrm{C}, 4.8 \mathrm{MPa}$; c) $140^{\circ} \mathrm{C}, 4.8 \mathrm{MPa}$; d) $180^{\circ} \mathrm{C}, 13.8 \mathrm{MPa}$; e) $250^{\circ} \mathrm{C}, 10.3$ MPa. Symbols are data [2]; solid lines and dashed lines are the CPA-C3 and CPA-C5 models, respectively. 
Table 10. Comparison of measured and modeled feed, light phase, and heavy phase compositions of pentane diluted bitumen at $180^{\circ} \mathrm{C}$ and $4.8 \mathrm{MPa}$. Experimental data from Johnston et al [2]; CPAC5 and CPA-C3 are the model approaches.

\begin{tabular}{lccccccc}
\hline & \multicolumn{3}{c}{ Measured } & \multicolumn{2}{c}{ CPA-C5 } & \multicolumn{2}{c}{ CPA-C3 } \\
\cline { 2 - 8 } Component & $\begin{array}{c}\text { Feed } \\
\text { wt\% }\end{array}$ & $\begin{array}{c}\text { Light } \\
\text { Phase } \\
\text { wt\% }\end{array}$ & $\begin{array}{c}\text { Heavy } \\
\text { Phase } \\
\text { wt\% }\end{array}$ & $\begin{array}{c}\text { Light } \\
\text { Phase } \\
\text { wt\% }\end{array}$ & $\begin{array}{c}\text { Heavy } \\
\text { Phase } \\
\text { wt\% }\end{array}$ & $\begin{array}{c}\text { Light } \\
\text { Phase } \\
\text { wt\% }\end{array}$ & $\begin{array}{c}\text { Heavy } \\
\text { Phase } \\
\text { wt\% }\end{array}$ \\
\hline 59 wt\% C5 & & & & & & & \\
$n$-Pentane & 59.2 & 67.1 & 31.4 & 64.5 & 19.9 & 65.3 & 23.4 \\
C5-Maltenes & 32.9 & 29.8 & 20.4 & 33.6 & 29.3 & 32.4 & 35.3 \\
C5-Asphaltenes & 8.0 & 3.1 & 48.2 & 1.9 & 50.8 & 2.3 & 41.2 \\
64 wt\% C5 (1) & & & & & & & \\
$n$-Pentane & 64.4 & 68.0 & 26.0 & 70.4 & 18.0 & 69.5 & 21.8 \\
C5-Maltenes & 28.7 & 29.0 & 29.6 & 28.6 & 25.0 & 28.0 & 33.7 \\
C5-Asphaltenes & 6.9 & 3.0 & 52 & 0.9 & 57.0 & 0.8 & 44.5 \\
64 wt\% C5 (2) & & & & & & & \\
$n$-Pentane & 63.7 & 72.8 & 19.2 & 69.5 & 17.7 & 70.7 & 22.1 \\
C5-Maltenes & 29.3 & 24.7 & 24.0 & 28.0 & 24.1 & 28.3 & 34.0 \\
C5-Asphaltenes & 7.0 & 2.6 & 56.8 & 0.8 & 58.2 & 1.0 & 43.9 \\
73 wt\% C5 & & & & & & & \\
$n$-Pentane & 72.5 & 77.9 & 20.3 & 77.6 & 15.6 & 78.2 & 19.7 \\
C5-Maltenes & 22.2 & 20.0 & 23.7 & 22.1 & 17.9 & 21.5 & 31.1 \\
C5-Asphaltenes & 5.4 & 2.1 & 56.0 & 0.3 & 66.5 & 0.3 & 49.2 \\
\hline
\end{tabular}

\subsection{Propane Diluted Bitumen}

Figure 4 shows the saturation pressures (L/VL boundaries) and onsets (L/LL boundaries) for the propane diluted bitumen from Dataset 1 . Note, the onset at $75^{\circ} \mathrm{C}$ and the saturation pressure at $20^{\circ} \mathrm{C}$ were not reported. The CPA-C5 approach (dashed lines) matched the saturation pressure data to within the experimental error $( \pm 0.4 \mathrm{MPa})$. A small VLL region was predicted at 90 and $135^{\circ} \mathrm{C}$, consistent with the observed VLL/VL boundary at $90^{\circ} \mathrm{C}$ and $50 \mathrm{wt} \%$ feed propane content, Figure $4 \mathrm{~d}$.

The CPA-C5 approach could not match the observed pressure dependence of the L/LL boundary, but rather predicted a pressure independent boundary, Figure 4. Hence, the model could only be tuned to match the onset at one pressure. The same issue was encountered by Mancilla-Polanco et 
al. [33] when modeling the same dataset with the Peng Robinson equation of state. Hence, this model deficiency may be an inherited issue from the cubic equation of state.

The CPA-C3 approach (solid lines in Figure 4) also matched the saturation pressures of the propane diluted bitumen from Dataset 1 to within the experimental error. Unlike the CPA-C5 approach, no VLL region was predicted at 90 and $135^{\circ} \mathrm{C}$. This result contradicts the experimentally confirmed existance of a VLL region at $90^{\circ} \mathrm{C}$, Figure $4 \mathrm{~d}$. At $135^{\circ} \mathrm{C}$, the light liquid phase was predicted to become supercritical above approximately $60 \mathrm{wt} \%$ propane in the feed and, therefore, there is no LL/VL boundary at higher propane contents, Figure 4e. The disappearance of the LL/VL boundary was also observed experimentally [33]. As with the CPA-C5 approach, the CPAC3 approach was unable to predict the pressure dependence of the onsets.

Figure 5 shows the C5-asphaltene and C3-asphaltene yield curves for the bitumen from Dataset 1 diluted with propane at temperatures from 20 to $135^{\circ} \mathrm{C}$ and pressures up to $10 \mathrm{MPa}$. "С3asphaltene" denotes the solvent free material in the heavy phase and " $\mathrm{C} 5$-asphaltene” denotes the $n$-pentane insoluble fraction. The CPA-C5 approach (dashed lines) was not able to predict that all C5-asphaltenes immediately partition into the heavy phase just above the onset. It approximately matched the $\mathrm{C} 5$-asphaltene yields at temperatures up to $90^{\circ} \mathrm{C}$ but drastically under-predicted the $\mathrm{C} 3$-asphaltene yields at all conditions below the critical temperature of propane $\left(96.6^{\circ} \mathrm{C}\right)$. The CPA-C5 approach underpredicted the C3-asphaltene yield is because too few pseudo-components were designated as self-associating components and therefore not enough of the bitumen could partition to the heavy phase. One potential solution is to tune the binary interaction parameters of some of the C5-maltene/propane pairs to force them partition into the heavy phase. However, composition dependent binary interaction parameter would then be required to match the yield curves (not shown here).

The CPA-C3 approach (solid lines in Figure 5) provided a significantly better prediction of yields below the critical temperature of propane with the average deviations of $6 \mathrm{wt} \%$. However, this approach consistently under-predicted the C5-asphaltene yields just above the onset. This error could be corrected by adjusting the binary interaction parameter between maltenes and propane but then the match to the saturation pressures would be lost. At $135^{\circ} \mathrm{C}$, the CPA-C3 approach 
predicted that all of the bitumen partitioned into the heavy phase at the onset and over-predicted the C3-asphaltene yield at propane content below $80 \mathrm{wt} \%$. It is not clear how much the model really deviates from the data because the experimental error in the yield data was reported to be highest near the onset [33].

Table 11 lists the measured and modeled phase compositions at feed propane contents of 50 and $75 \mathrm{wt} \%$ at temperatures from 50 to $130^{\circ} \mathrm{C}$ and pressures up to $10 \mathrm{MPa}$. Since the CPA-C5 approach failed to match the C3-asphaltene yields, the predicted phase compositions from this model will not be discussed. The CPA-C3 approach matched the measured compositions with an average absolute deviation of $5 \mathrm{wt} \%$ for the light phase and $6 \mathrm{wt} \%$ for the heavy phase. Up to $90^{\circ} \mathrm{C}$, the model predicted too little partioning of propane and maltenes to the heavy phase. At $130^{\circ} \mathrm{C}$, the error reversed, and the model predicted too much partioning of propane and maltenes to the heavy phase. The change in pattern corresponds to the change in the shape of the predicted yield curves in Figure 5. 

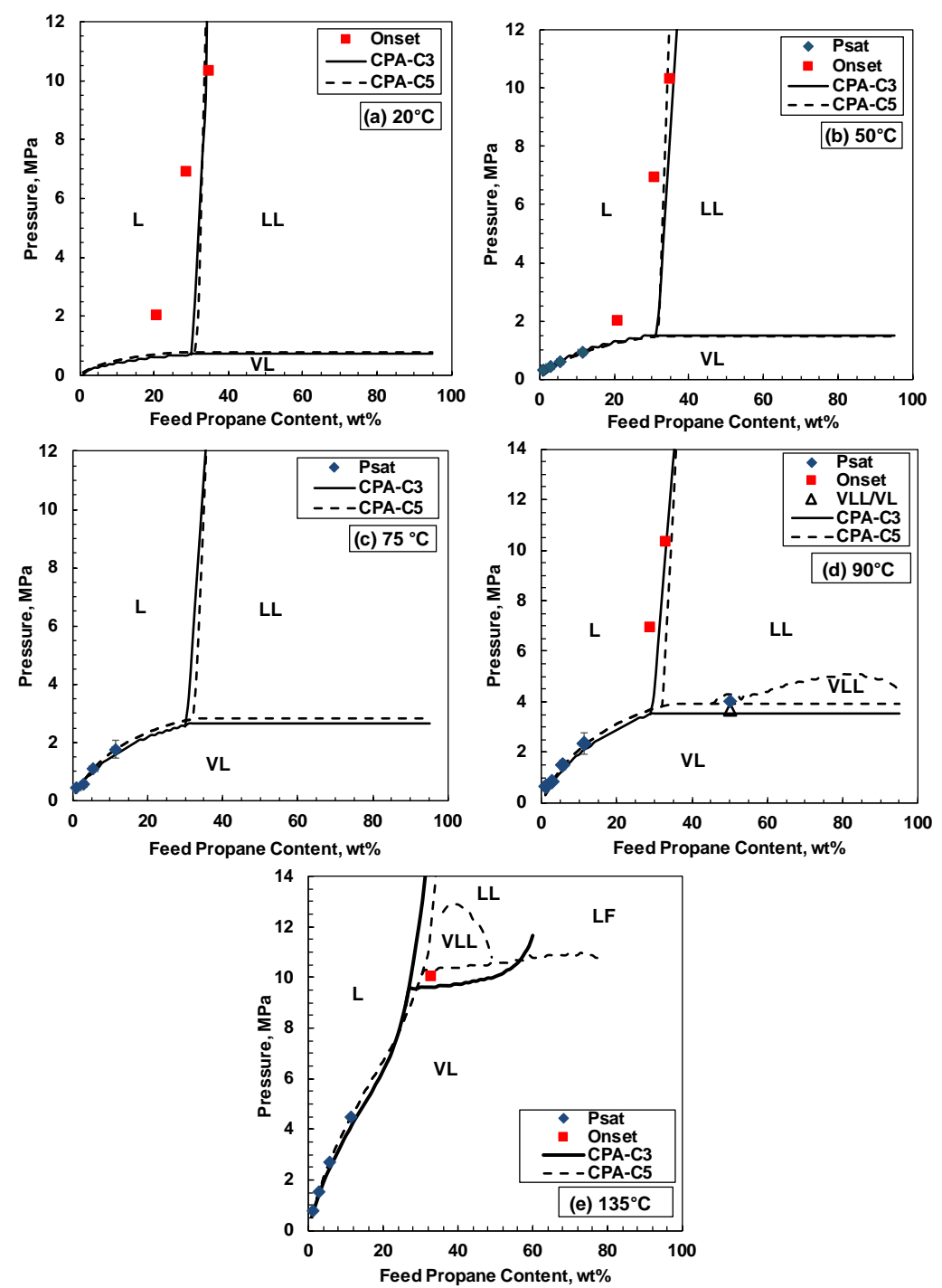

Figure 4. Pressure-composition diagram showing the saturation pressures and liquid-liquid boundaries for propane diluted WC-B-C3 bitumen from Dataset 1 at: a) $20^{\circ} \mathrm{C}$; b) $50^{\circ} \mathrm{C}$; c) $75^{\circ} \mathrm{C}$; d) $90^{\circ} \mathrm{C}$; e) $135^{\circ} \mathrm{C}$. Symbols are data [33]; solid lines and dashed lines are the CPA-C3 and CPAC5 approaches, respectively. LF stands for liquid-fluid region. 

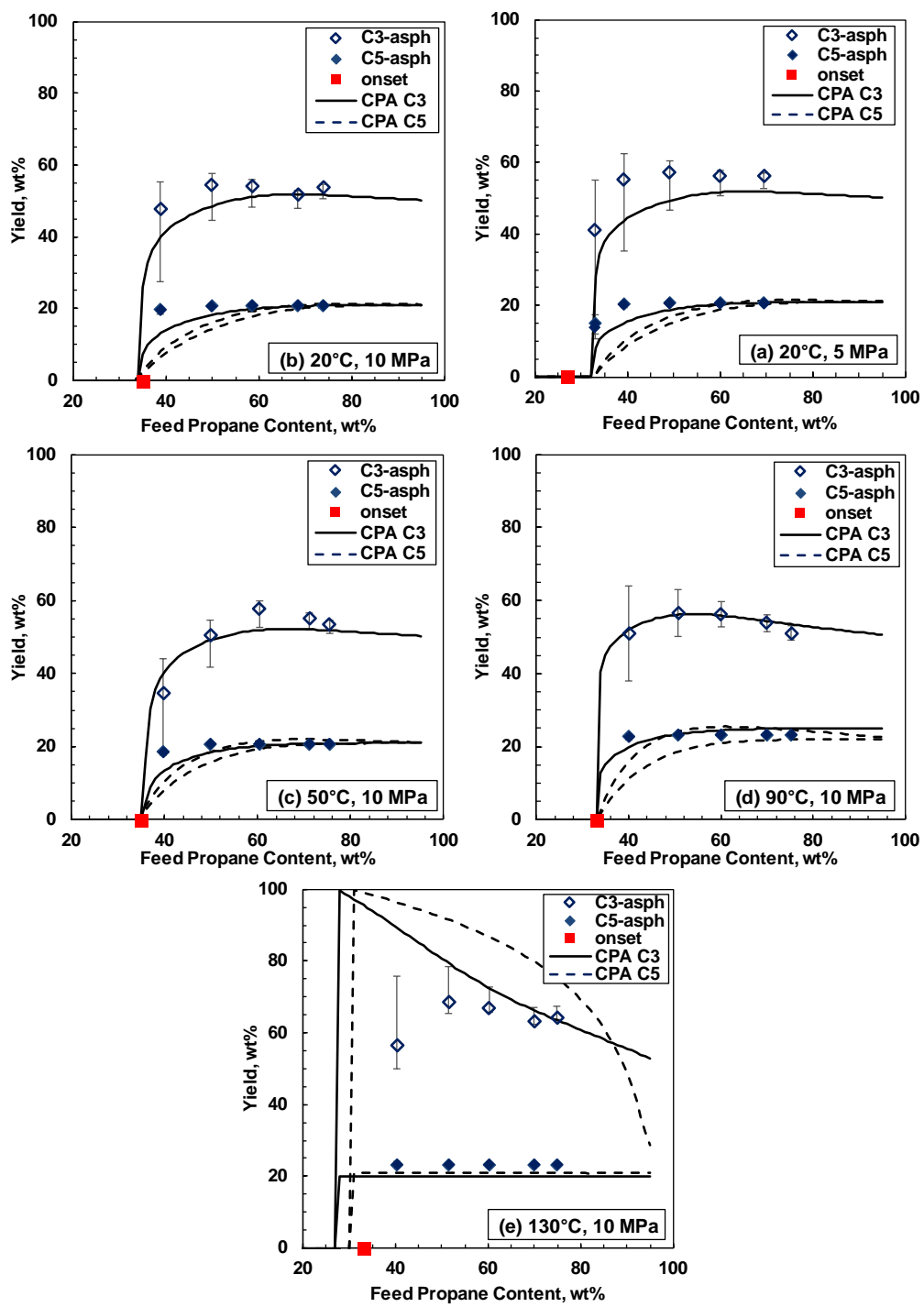

Figure 5. C3-asphaltene yield and C5-asphaltene yields from propane diluted WC-B-B3 bitumen at: a) $20^{\circ} \mathrm{C}, 5 \mathrm{MPa}$; b) $20^{\circ} \mathrm{C}, 10 \mathrm{MPa}$; ) $50^{\circ} \mathrm{C}, 10 \mathrm{MPa}$; d) $90^{\circ} \mathrm{C}, 10 \mathrm{MPa}$; e) $130^{\circ} \mathrm{C}, 10 \mathrm{MPa}$. Symbols are data [33]; solid lines and dashed lines are the CPA-C3 and CPA-C5 models, respectively. 
Table 11. Comparison of measured and modeled feed, light phase, and heavy phase compositions of propane diluted bitumen. Experimental data from Mancilla-Polanco et al [33]; CPA-C3 is the modeling approach.

\begin{tabular}{|c|c|c|c|c|c|}
\hline \multirow[b]{2}{*}{ Component } & \multicolumn{3}{|c|}{ Measured } & \multicolumn{2}{|c|}{ CPA-C3 } \\
\hline & $\begin{array}{l}\text { Feed } \\
\mathrm{wt} \%\end{array}$ & $\begin{array}{c}\text { Light Phase } \\
\text { wt } \%\end{array}$ & $\begin{array}{c}\text { Heavy Phase } \\
\text { wt } \%\end{array}$ & $\begin{array}{c}\text { Light Phase } \\
\text { wt } \%\end{array}$ & $\begin{array}{c}\text { Heavy Phase } \\
\text { wt } \%\end{array}$ \\
\hline \multicolumn{6}{|l|}{$50^{\circ} \mathrm{C}, 2 \mathrm{MPa}$} \\
\hline Propane & 49.5 & 72.6 & 22.1 & 64.4 & 21.7 \\
\hline C5-maltene & 40.8 & 27.3 & 56.4 & 34.7 & 50.4 \\
\hline C5-Asphaltenes & 9.7 & 0.0 & 21.5 & 0.9 & 27.9 \\
\hline \multicolumn{6}{|l|}{$50^{\circ} \mathrm{C}, 2 \mathrm{MPa}$} \\
\hline Propane & 74.2 & 88.0 & 20.7 & 85.1 & 19.9 \\
\hline C5-maltene & 20.8 & 12.0 & 53.5 & 14.9 & 49.6 \\
\hline C5-Asphaltenes & 5.0 & 0.0 & 25.8 & 0.0 & 30.5 \\
\hline \multicolumn{6}{|l|}{$50^{\circ} \mathrm{C}, 5 \mathrm{MPa}$} \\
\hline Propane & 49.7 & 69.6 & 26.8 & 64.2 & 21.5 \\
\hline C5-maltene & 40.6 & 30.3 & 51.7 & 35.8 & 48.5 \\
\hline C5-Asphaltenes & 9.7 & 0.0 & 21.5 & 0.1 & 30.0 \\
\hline \multicolumn{6}{|l|}{$90^{\circ} \mathrm{C}, 6.9 \mathrm{MPa}$} \\
\hline Propane & 49.5 & 76.9 & 18.4 & 66.4 & 16.3 \\
\hline C5-maltene & 40.8 & 23.1 & 61.6 & 33.6 & 53.2 \\
\hline C5-Asphaltenes & 9.7 & 0.0 & 20.0 & 0.0 & 30.5 \\
\hline \multicolumn{6}{|l|}{$130^{\circ} \mathrm{C}, 10 \mathrm{MPa}$} \\
\hline Propane & 50.0 & 79.8 & 1.8 & 71.0 & 15.8 \\
\hline C5-maltene & 40.4 & 20.2 & 70.2 & 29.0 & 57.9 \\
\hline C5-Asphaltenes & 9.6 & 0.0 & 28.0 & 0.0 & 26.3 \\
\hline
\end{tabular}

\subsection{Other Conditions, Oils, and Solvents}

\section{Independent Bitumen/Propane Data at Other Conditions}

Dataset 2 includes L/VL and LL/VLL boundaries, but no L/LL boundaries, for propane diluted Peace River bitumen and it is used to examine the CPA-EoS predictions in this region. Recall that the bitumen in Dataset 2 is similar to the bitumen in Dataset 1 and the same characterization was assumed to apply. Figure 6 shows the measured and modeled L/VL and LL/VLL phase boundaries. The CPA-C3 approach was used. Below the critical temperature of propane $\left(96.6^{\circ} \mathrm{C}\right)$, the CPAC3 approach slightly underpredicted the L/VL boundaries but was generally within $\pm 0.2 \mathrm{MPa}$ of the data. The LL/VLL boundaries were consistently underpredicted by approximately $0.5 \mathrm{MPa}$. 
Above the critical temperature of propane, both boundaries were significantly overpredicted. In addition, the experimental L/VL and LL/VLL boundaries suggest that, for this propane diluted bitumen, the onset of asphaltene precipitationan (L/LL boundary) is above $40 \mathrm{wt} \%$ propane content in the feed at temperatures above $90^{\circ} \mathrm{C}$. The experimental boundaries also suggest that the onset of asphaltene precipitation is less than $35 \mathrm{wt} \%$ propane content at temperatues below $90^{\circ} \mathrm{C}$. Note, that the CPA-C3 approach underpredicts the onsets at all tested temperatures. The reason for these deviations is unknown; however, it might be possible that that the bitumen from Dataset 2 has a different distribution of properties than the bitumen from Dataset 1, affecting the performance of the CPA-EoS. Whatever the reason for the difference, the model fit to the data can be improved if the model is tuned to the experimental data.
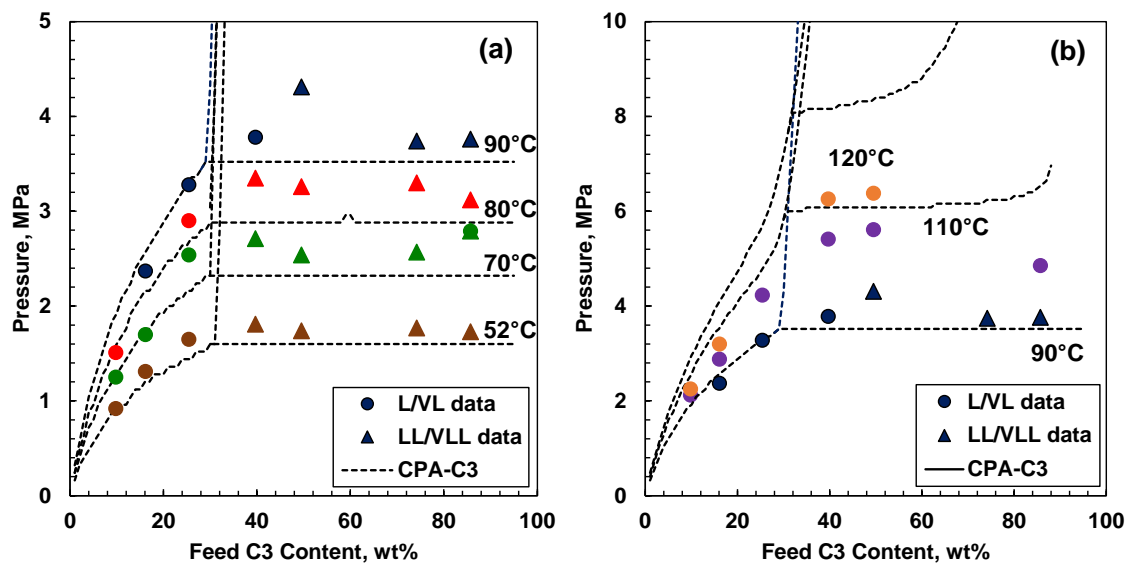

Figure 6. Measured and modeled saturation pressures for propane diluted Peace River bitumen from Dataset 2 [3]: a) 52 to $90^{\circ} \mathrm{C}$; b) 90 to $120^{\circ} \mathrm{C}$.

\section{Different Oils and Solvents}

Figures 7 and 8 show the yield curves for the four diluted oils in Dataset 3 at 23 and $0^{\circ} \mathrm{C}$, respectively. Recall that for each oil, the model was tuned to match the onset in $n$-heptane at $23^{\circ} \mathrm{C}$ by adjusting only one parameter, $\left(\varepsilon^{A A} / R\right)^{\circ}$ (Section 4.3$)$. The effect of the solvent was accounted for with the asphaltene/solvent cross-association energies (Figure 1a for CPA-C5 and Figure 1b 
for CPA-C3). Both approaches matched the yield data at $23^{\circ} \mathrm{C}$ with average deviations within \pm 0.5 wt\%.
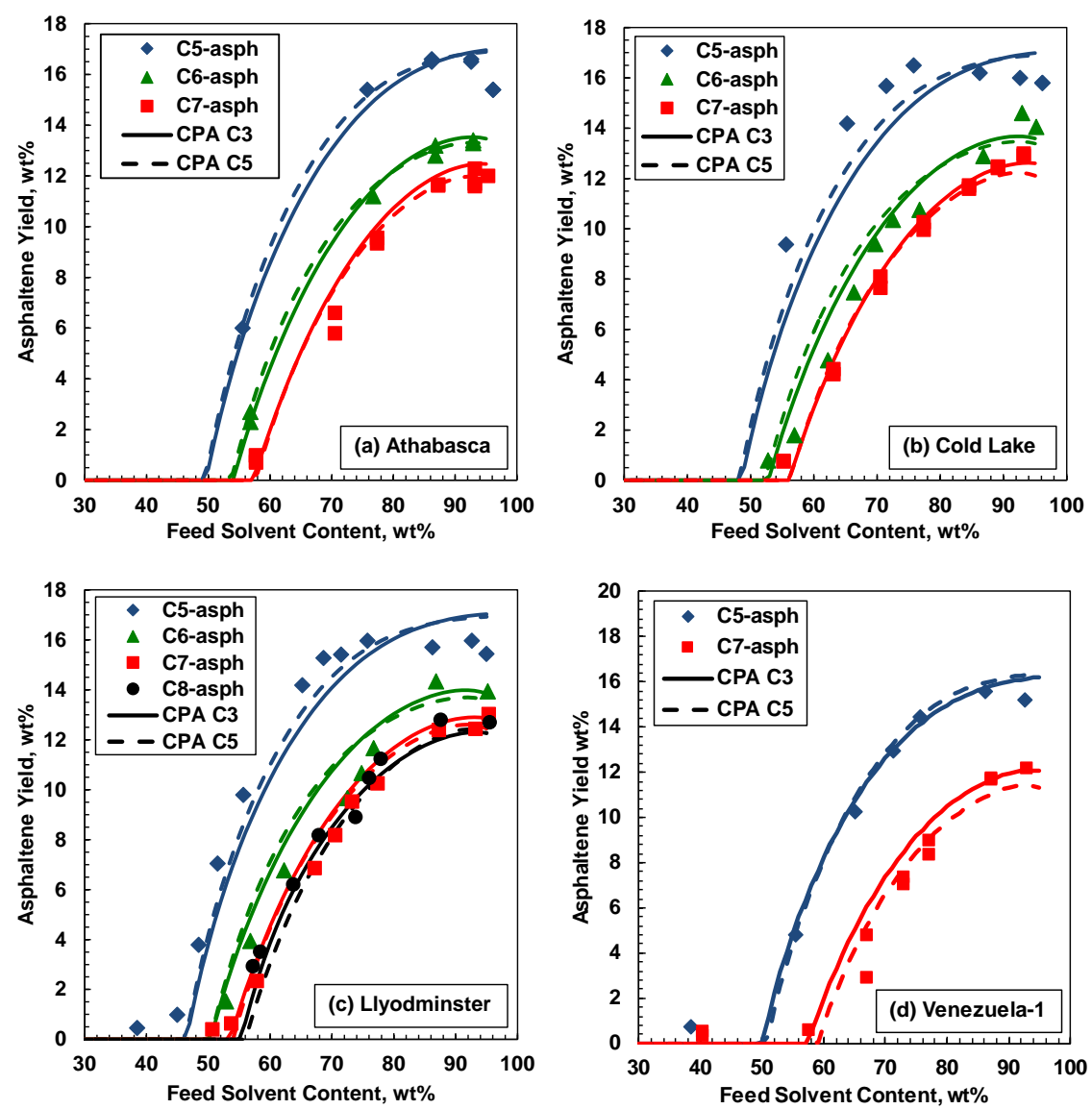

Figure 7. Measured and modeled asphaltene yields for four different bitumens at $23^{\circ} \mathrm{C}$ and 0.1 MPa: (a) Athabasca (b) Cold Lake (c) Lloydminster and (d) Venezuela-1. Symbols are data [34]; solid lines and dashed lines are the CPA-C3 and CPA-C5 approaches, respectively.

To model the data at $0^{\circ} \mathrm{C}$, the temperature dependent cross-association parameter between the asphaltene and maltene pseudo-components (Eq. 13 for the CPA-C5 approach, Eq. 16 and 17 for the CPA-C3 approach) was extrapolated to $0^{\circ} \mathrm{C}$; no other parameters were adjusted. Both models matched the yield data with deviations within $\pm 2.5 \mathrm{wt} \%$ of the experimental data. The largest errors 
were found for the Cold Lake and the Venezuela- 1 bitumens at $0^{\circ} \mathrm{C}$ at higher dilutions. The most likely explanation is that the temperature dependence of the asphaltene/maltene cross-association energy for these oils is not the same as that for the oils from Dataset 1 . Therefore, the extrapolation of the cross-association parameter between the asphaltene and maltene pseudo-components is inaccurate.
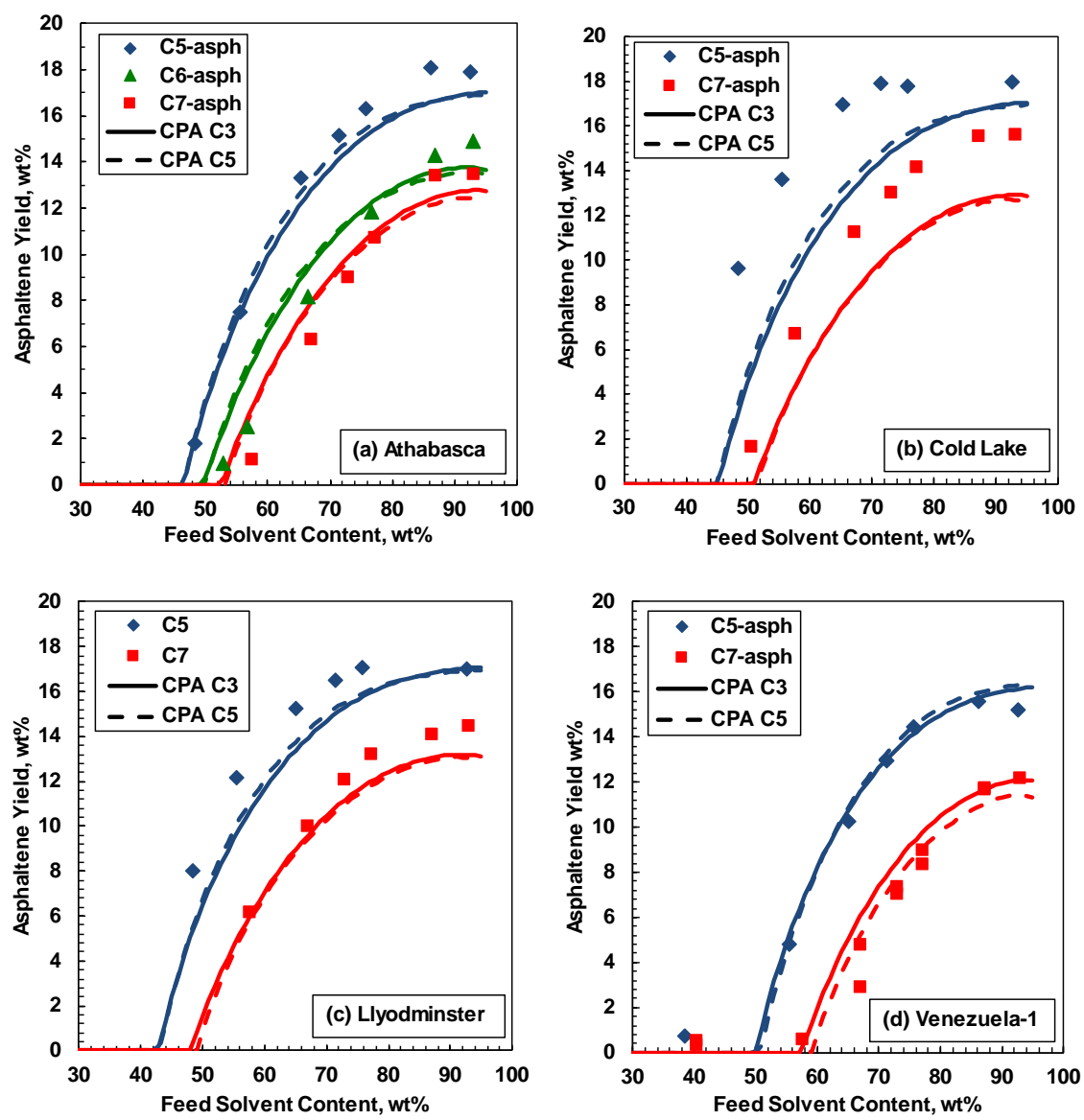

Figure 8. Measured and modeled asphaltene yields for four different bitumens at $0^{\circ} \mathrm{C}$ and $0.1 \mathrm{MPa}$ : (a) Athabasca (b) Cold Lake (c) Lloydminster and (d) Venezuela-1. Symbols are data [34]; solid lines and dashed lines are the CPA-C3 and CPA-C5 approaches, respectively. 


\subsection{Order of Precipitation}

It is known that the most strongly self-associating asphaltene fractions tend to precipitate preferentially. For example, when an $n$-alkane is added to a bitumen, the most strongly associated asphaltenes precipitate near the onset and the less strongly associated asphaltenes precipitate as the yield increases at higher dilution. Similarly, only the more strongly associated asphaltenes precipitate when the oil is diluted with a higher carbon number $n$-alkane. The less strongly associated asphaltenes also precipitate in the lower carbon number $n$-alkanes where yields are higher. Recall that one objective of this study was to better capture this sequential precipitation. The correct allocation of self-associating species is important for predicting the phase behavior of crude oil fractions (such as deasphalted oil) particularly if later blended with other oils or solvents that can potentially cause asphaltene precipitation.

Figure 9 shows the distribution of the asphaltene fractions in the heavy phase at different $n$-pentane contents in the feed for the Athabasca bitumen from Dataset 3. Both the CPA-C5 approach (Figure 9a) and the CPA-C3 approach (Figure 9b) predicted that the most self-associating species precipitate preferentially. For example, for the CPA-C5 approach just above the onset, the Asph6 (strongest self-associating fraction) yield is three times more than Asph-1 (weakest selfassociating fraction) yield. As the $n$-pentane content increases, all of the fractions precipitate and their yields are the same. Similar results were obtained for propane diluted bitumen.

Figure 10 shows the fractional precipitation (mass of fraction in heavy phase divided by mass in feed) of each asphaltene pseudo-component from Athabasca bitumen from Dataset 3 diluted with $n$-pentane, $n$-hexane, and $n$-heptane each at $23^{\circ} \mathrm{C}, 0.1 \mathrm{MPa}$, and $95 \mathrm{wt} \%$ solvent in the feed. At these conditions, the most strongly self-associating asphaltenes (highest fraction numbers) always precipitate. The less strongly associated asphaltenes precipitate sequentially when the solvent is switched from $n$-heptane to $n$-hexane to $n$-pentane. Unfortunately, there were no data with which to validate the model predictions but both the CPA-C3 and CPA-C5 models qualitative capture the sequential precipitation of more to less self-associated asphaltenes. 

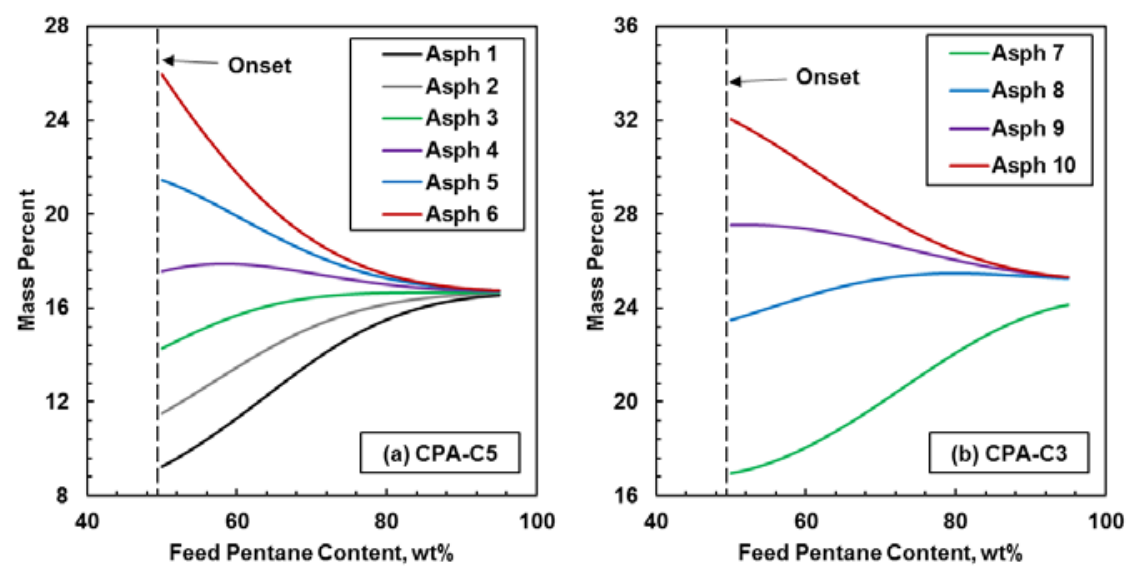

Figure 9. Predicted composition of the heavy phase from the Athabasca bitumen from Dataset 3 diluted with $n$-pentane at $23^{\circ} \mathrm{C}$ and $0.1 \mathrm{MPa}$ a) CPA-C5 approach; b) CPA-C3 approach.
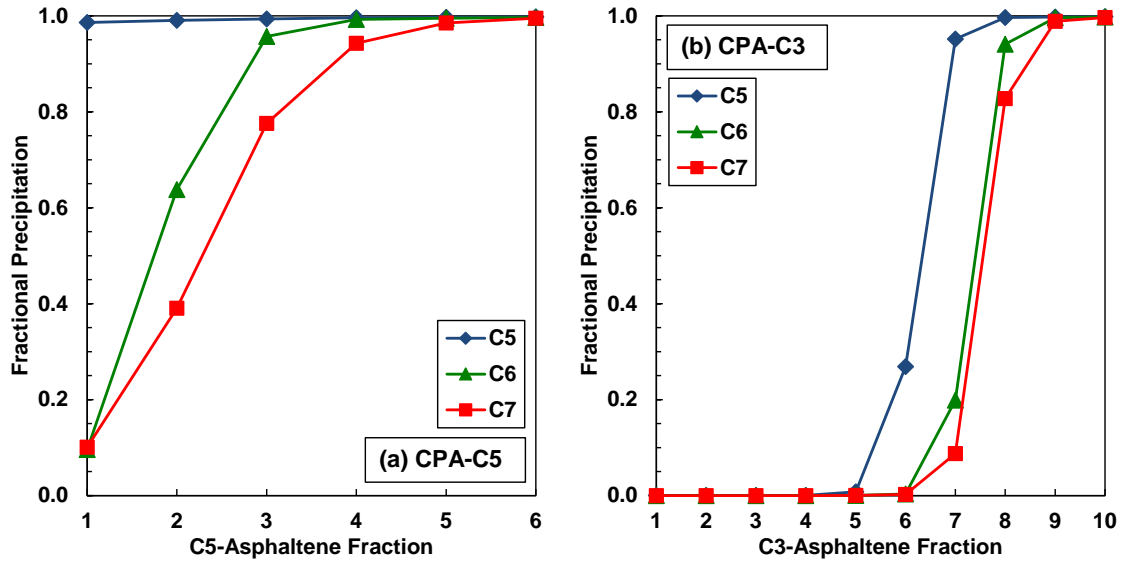

Figure 10. Fractional precipitation of each asphaltene fraction from the CPA-C5 approach (a) and from the CPA-C3 approach (b) for Athabasca bitumen diluted with $n$-pentane, $n$-hexane, and $n$ heptane at $23^{\circ} \mathrm{C}$ and $0.1 \mathrm{MPa}$, from Dataset 3. The solvent content in the feed is $95 \mathrm{wt} \%$ for all cases. 


\subsection{Effect of Lumping Pseudo-Components}

In practical applications, the components are often lumped to improve the speed of the simulation. Here, the impact of lumping on the accuracy of the phase behavior predictions was assessed according to the lumping schemes presented in Table 12. The parameters of the lumped pseudocomponents for the cubic terms in the CPA were calculated with the mixing rules (Eqs. 6 and 7). The only CPA parameters that required adjustment after lumping were the asphaltene selfassociation energy and asphaltene-solvent cross association energy. They were adjusted as discussed below. The effect of lumping on the phase boundary and yield curve predictions was similar for both the CPA-C5 and CPA-C3 approaches and only the results for the CPA-C3 approach are shown below. Note, in general, the CPA-C5 approach is $40 \%$ faster than the CPAC3 approach because it includes less self-associating components.

\section{Lumping Maltenes}

Lumping maltenes into one pseudo-component had negligible impact on the calculated phase boundaries and yields, and, the results are not shown here. The most important difference is the increase of the number of flashes per second, from 50 for the full characterization (Section 4) to 90 for the maltenes lumped as one single pseudo-component, Table 12. Therefore, for calculation of phase boundaries and yields, it is recommended to lump the maltenes as a single pseudocomponent.

Table 12. Flash calculation speed for different lumping schemes for the CPA-C3 approach. Note that the speed can vary $\pm 10 \%$ depending on the location within the phase diagram. Full oil characterization was presented in Section 4. PC stands for pseudo-component.

\begin{tabular}{lccc}
\hline \multicolumn{1}{c}{ Lumping Scheme } & $\begin{array}{c}\text { Number } \\
\text { Maltene PC }\end{array}$ & $\begin{array}{c}\text { Number } \\
\text { Asphaltene PC }\end{array}$ & $\begin{array}{c}\text { Flashes per } \\
\text { second }\end{array}$ \\
\hline Full characterization & 6 & 10 & 50 \\
Lumping maltenes & 1 & 10 & 90 \\
Lumping asphaltenes (5) & 6 & 5 & 147 \\
Lumping asphaltenes (1) & 6 & 1 & 440 \\
Lumping both (5 asph) & 1 & 5 & 539 \\
Lumping both (1 asph) & 1 & 1 & 1507 \\
\hline
\end{tabular}




\section{Lumping Asphaltenes}

The model sensitivity to the number of asphaltene pseudo-components was also tested. Only results for the CPA-C3 approach are shown here. This approach was tested on the propane and pentane diluted bitumen from Dataset 1 . The reduced asphaltene-solvent cross-association energy was set to $2000 \mathrm{~K}$ for all propane/asphaltene pseudo-component pairs. For pentane diluted bitumen, the cross-association energy trend was tuned for each lumping scheme in order to obtain the best match of both onset and yield curves. The original relative trends were preserved (Figure 1b); only the magnitudes were adjusted.

Lumping the asphaltenes did not have any impact on the predicted phase boundaries. It also had negligible impact on the predicted yields for propane diluted bitumen, Figure 11a. This result indicates that the shape of the propane diluted bitumen yield curve is independent of the distribution of self-association energies of asphaltenes. Recall that the shape of the yield curve was captured by adjusting asphaltene pseudo-component self-association energies, Section 4. However, the ability to predict the order of precipitation will be lost with a single asphaltene pseudocomponent and therefore predictions for bitumen fractions may be compromised.
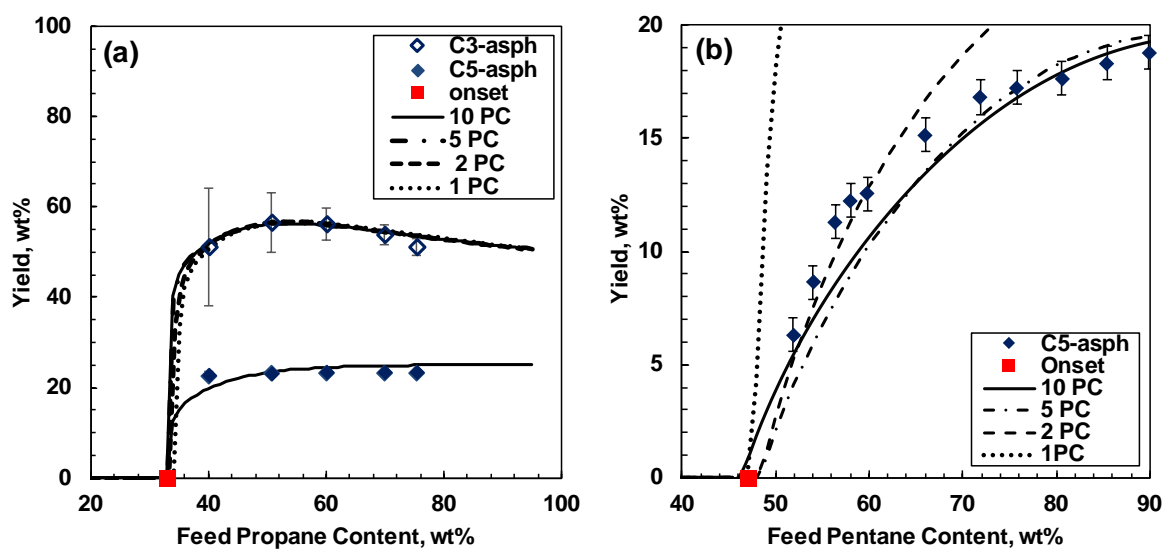

Figure 11. Effect of lumping asphaltene pseudo components on onset and yield curve predictions for: a) propane diluted bitumen in Dataset 1 at $90{ }^{\circ} \mathrm{C}, 10 \mathrm{MPa}$; b) $n$-pentane diluted bitumen in Dataset 1 at $20^{\circ} \mathrm{C}, 0.1 \mathrm{MPa}$. PC stands for number of asphaltene pseudo-components. 10 PC refers to the full oil characterization, Table 12. The maltene fraction was represented as a single pseudocomponent. 
Lumping significantly impacted the predicted yields for $n$-pentane diluted bitumen, Figure $11 \mathrm{~b}$. In $n$-pentane diluted bitumen, only some of the asphaltenes precipitate and the ability of the model to predict the yields at different solvent contents depends on the distribution of self-association energies in the asphaltenes. This distribution is lost when the components are lumped too extensively. A minimum of 5 asphaltene pseudo-components was required to maintain the predictions of both onset and yield curves. Lumping into a single pseudo-component was not viable because it was not possible to match both the onset and the yield. Therefore, at least 5 asphaltene pseudo-components are recommended. Table 12 shows that lumping the asphaltene pseudo-components can increase the flash calculation speed up to 1500 flashes per second depending on the amount of lumping.

\subsection{General Application and Limitations of Model}

In this study, the proposed methodology has only been tested on bitumens diluted with solvents. The characterization must have a content of self-associating components equal or greater than the asphaltene content defined as the mass fraction of the oil that is insoluble in the given solvent. Hence, the CPA-C3 characterization is required to model yields from propane diluted bitumen or higher carbon number $n$-alkanes. The CPA-C5 characterization can be used for $n$-pentane diluted bitumen or higher carbon number $n$-alkanes. The CPA-C5 approach is less computationally intensive and is $40 \%$ faster than CPA-C3 approach. In both cases, the only tuning parameter for different bitumen is the asphaltene self-association energy. The only tuning parameter for different solvents is the asphaltene-solvent cross-association energy. The CPA-C3 and CPA-C5 approaches are also suitable for predicting the stability of oil blends but have not yet been tested for this application.

Both the CPA-C3 and CPA-C5 approaches can be extended to live oil applications as shown by Arya et al [28, 30] for a similar C5-asphaltene based characterization. Briefly, the proposed characterization is taken to represent the heavy residue of a conventional oil. The lighter components are added to the characterization usually based on a GC assay. Arya et al. [28] adjusted the critical properties of the lumped maltenes to match the bubble point of the oil. Another option is to adjust the binary interaction parameter between methane and the residue pseudo-components. 
The former approach has successfully matched the onset of asphaltene precipitation from a live oil depressurization or from the injecting of mixtures of carbon dioxide and nitrogen into crude oil. The proposed methodology has the following limitations:

1. The model required additional tuning and the predicted phase boundaries were less reliable above the critical temperature of the solvent.

2. The pressure dependence of the liquid-liquid boundary (which becomes significant as the temperature approaches the critical temperature of the solvent) could not be accurately captured. The model could only be tuned to match the liquid-liquid boundary at a single pressure point at any given temperature.

3. The temperature dependence of the maltene-asphaltene cross-association energy was different for propane than for the higher carbon number $n$-alkanes. The correlation may need to be tuned for other solvents with critical temperatures close the operational temperatures of interest.

4. The model tuning is not robust; sometimes changing one parameter will require retuning of several other parameters. For example, if the self-association energy distribution of asphaltenes is retuned to match yield data, it is likely that the other already established correlations such as those for the asphaltene-maltene and asphaltene-solvent crossassociation energies will also require re-tuning.

5. The model is tunable when data are available but is not likely to be predictive for significantly different oils, solvents, or temperatures and pressures beyond the tuned conditions.

If a model is to be created from scratch or retuning is required, the following step-wise approach is recommended:

1. Divide the bitumen into pseudo-components based on distillation data and the required asphaltene content (e.g. C5-asphaltenes for pentane and higher carbon number solvents).

2. Define the asphaltene pseudo-components as self-associating species and the maltene pseudo-components as non-associating species.

3. Assign the equation of state parameters as described previously.

4. Adjust the maltene-solvent binary interaction parameter to match saturation pressures.

5. Tune both $\left(\varepsilon^{A i A i} / R\right)^{\circ}$ and $\varepsilon^{A s p h M a l t} / R$ to match the onset at a given temperature and pressure. 
6. Adjust the $\varepsilon^{\text {AsphMalt }} R$ at several other temperatures and establish a correlation to temperature.

7. To match the shape of the yield curve, tune the $\varepsilon^{A i A i} / R$ distribution or the $\varepsilon^{A s p h S o l v} / R$ distribution.

8. Return to Step 3 and iterate until all phase behavior data matched.

\section{Conclusions}

Two oil characterizations were developed for the CPA model applied to the phase behavior of mixtures of bitumen and $n$-alkanes: 1 ) the CPA-C5 approach with the fraction of self-associating components based on the $n$-pentane insoluble content (19 wt\% of the bitumen); 2) the CPA-C3 approach based on the propane insoluble content (50 wt\% of the bitumen). The CPA-C5 model was less complex and ran $40 \%$ faster but could not match the yield and phase composition data for propane diluted bitumen. The key to matching yield data is that self-associating components must equal or exceed the content on the oil that is insoluble in the given solvent.

Within their range of applicability, both approaches matched the phase boundaries and yields generally to within the measurement error. The approaches matched the phase compositions generally to within $11 \mathrm{wt} \%$ or less with the average absolute deviations listed below:

\begin{tabular}{l|cc|cc}
\multirow{2}{*}{ Solvent } & \multicolumn{2}{|c|}{ CPA-C3 (AAD in \%) } & \multicolumn{2}{c}{ CPA-C5 (AAD in \%) } \\
& Light Phase & Heavy Phase & Light Phase & Heavy Phase \\
\hline Propane & 5 & 6 & N/A & N/A \\
$n$-Pentane & 2 & 7 & 2 & 5
\end{tabular}

One advantage of the proposed approaches is that no composition dependent parameters were required to fit the data. Previous work with a cubic equation of state found that it could match the same dataset used in this study only by using composition dependent binary interaction parameters [39]. It is possible that these binary interaction parameters were indirectly accounting for the effect of self-association.

The proposed approaches also address a physical inconsistency in previous attempts to use CPA to match yield curves of asphaltene precipitation from $n$-alkane diluted bitumen [28, 31]. 
Previously, all asphaltene components were characterized identically so that all partitioned equally to the heavy phase. The proposed characterization assigns a range of self-association energies to the asphaltenes so that more strongly self-associating components partition preferentially to the heavy phase. This refinement potentially allows for more accurate prediction of the phase behavior of fractions separated from the original mixture.

Although the CPA approach could be tuned to match much of the observed bitumen/solvent phase behavior, asphaltene/solvent cross-association energies were required to fit the data although there is no physical basis for this type of association energy. Both models required additional tuning and were less accurate above the critical point of the solvent. The models also failed to predict the pressure dependence of the liquid-liquid boundary at temperatures approaching the critical temperature of the solvent. It appears that the model does not capture all of the physics underlying the observed phase behavior. Hence, the model is suitable for interpolative modeling over a wide range of conditions but extrapolation is risky.

The number of pseudo-components in either approach could be reduced to 1 non-associating component and 5 associating components with minimal loss of accuracy and a significant improvement in computational speed. However, both approaches have been tuned to match measured data and are not predictive. The approaches can be applied to other solvents by tuning the asphaltene/solvent cross-association energy. They can be applied to other bitumens by adjusting the self-association energy of the asphaltenes. Caution is advised if other parameters are adjusted because changes in one parameter may require retuning of several other parameters. Previous studies have shown that this type of characterization can easily be extended to live oils [26-30]. Hence, the proposed approaches can be adapted to all of the typically encountered crude oil and solvent phase behavior. Caution is advised when predicting LL behavior above the critical temperature of the solvent.

\section{Acknowledgements}

The authors would like to thank the sponsors of the Natural Science and Engineering Research Council of Canada (NSERC) Industrial Research Chair in Heavy Oil Properties and Processing, including NSERC, CNRL, Nexen Energy ULC., Petrobras, Schlumberger, Suncor, and Virtual 
Materials Group (VMG), for their financial support. We are grateful to Dr. Francisco Ramos

Pallares for his suggestions.

\section{References}

1. Sabbagh, O., Akbarzadeh, K., Badamchi-Zadeh, A., Svrcek, W., Yarranton, H.W., Applying the PR-EoS to Asphaltene Precipitation from $n$-Alkane Diluted Heavy Oils and Bitumens. Energy Fuels 2006. 20: 625-634.

2. Johnston, K.A., Schoeggl, F.F., Satyro, M.A., Taylor, S.D., Yarranton, H.W., Phase behavior of bitumen and n-pentane. Fluid Phase Equilibria 2017. 442: 1-19.

3. Dini, Y., Becerra, M., Shaw, J.M., Phase Behavior and Thermophysical Properties of Peace River Bitumen + Propane Mixtures from 303 K to 393 K. J. Chem. Eng. Data 2016. 61(8): 2659-2668.

4. Mehrotra, A., Svrcek, W.Y., Correlations and Prediction of Gas Solubility in Cold Lake Bitumen. Can. J. Chem. Eng. 1988. 66: 666-670.

5. Badamchi-Zadeh, A., Yarranton, H.W., Maini, B.B., Satyro, M.A., A. Phase Behavior and Physical Property Measurements for VAPEX Solvents: Part 2. Propane, Carbon Dioxide and Athabasca Bitumen. J. Can. Pet. Technol. 2009. 48: 57-65.

6. Badamchi-Zadeh, A., Yarranton, H.W., Svrcek, W., Maini, B.B., Phase Behavior and Physical Property Measurements for VAPEX Solvents: Part 1. Propane and Athabasca Bitumen. J. Can. Pet. Technol. 2009. 48: 54-61.

7. Jamaluddin, A.K.M., Kalogerakis, N.E., Chakma, A., Predictions of CO2 Solubility and CO2 Saturated Liquid Density of Heavy Oils and Bitumens using a Cubic Equation of State. Fluid Phase Equilibria 1991. 64: 33-48.

8. Gonzalez, D.L., Ting, D.P., Hirasaki, G.J., Chapman, W.G., Prediction of Asphaltene Instability under Gas Injection with the PC-SAFT Equation of State. Energy Fuels 2005. 19: 1230-1234.

9. Gonzalez, D.L., Vargas, F.M., Hirasaki, G.J., Chapman, W.G., Modeling Study of CO2Induced Asphaltene Precipitation. Energy Fuels 2008. 22: 757-762.

10. Tavakkoli, M., Panuganti, S.R., Taghikhani, V., Pishvaie, M.R., Chapman, W.G., Understanding the polydisperse behavior of asphaltenes during precipitation. Fuel 2014. 117: 206-217.

11. Yarranton, H.W., Masliyah, J.H., Molar mass distribution and solubility modeling of asphaltenes. AIChE J. 1996. 42(12): 3533-3543.

12. Badre, S., Goncalves, C.C., Norinaga, K., Gustavson, G., Mullins, O.C., Molecular size and weight of asphaltene and asphaltene solubility fractions from coals, crude oils and bitumen. Fuel 2006. 85(1): 1-11.

13. Arya, A., Liang, X., von Solms, N., Kontogeorgis, G.M., Modeling of asphaltene onset precipitation conditions with Cubic Plus Association (CPA) and Perturbed Chain Statistical 
Associating Fluid Theory (PC-SAFT) equations of state. Energy Fuels 2016. 30(8): 68356852.

14. Agrawala, M., Yarranton, H.W., Asphaltene association model analogous to linear polymerization. Industrial \& Engineering Chemistry Research 2001. 40: 4664-4672.

15. Speight, J.G., The Chemistry and Technology of Petroleum, 3rd ed. 1999. Marcel Dekker, New York.

16. Buch, L., Groenzin, H., Buenrostro-Gonzalez, E., Anderson, S.I., Lira-Galeana, C., Mullins, O.C., Molecular size of asphaltene fractions obtained from residuum hydrotreatment. Fuel 2003. 82(9): 1075-1084.

17. Wiehe, I.A., Kennedy, R.J., The oil compatibility model and crude oil incompatibility. Energy Fuels 2000. 14(1): 56-59.

18. Wang, J.X., Buckley, J.S., A two-component solubility model of the onset of asphaltene flocculation in crude oils. Energy Fuels 2001. 15(5): 1004-1012.

19. Alboudwarej, H., Akbarzadeh, K., Beck, J., Svrcek, W.Y., Yarranton, H.W., Regular Solution Model of asphaltene precipitation from bitumen. AIChE J. 2003. 49(11): 2948-2956.

20. Tharanivasan, A.K., Yarranton, H.W., Taylor, S.D., Application of regular solution based models to asphaltene orecipitation from live oils. Energy Fuels 2011. 25(2): 528-538.

21. Whitson, C.H., Brulé, M.R., Phase Behavior. 2000. Henry L. Doherty Memorial Fund of AIME, Society of Petroleum Engineers.

22. Castellanos Diaz, O., Modaresghazani, J., Satyro, M.A., Yarranton, H.W., Modeling the phase behavior of heavy oil and solvent mixtures. Fluid Phase Equilibria 2011. 304(1-2): 74-85.

23. Gross, J., Sadowski, G., Perturbed-Chain SAFT: An Equation of State Based on a Perturbation Theory for Chain Molecules. Industrial \& Engineering Chemistry Research 2001. 40(4): 1244-1260.

24. Kontogeorgis, G.M., Voutsas, E.C., Yakoumis, I.V., Tassios, D.P., An equation of state for associating fluids. Ind. Eng. Chem. Res. 1996. 35(11): 4310-4318.

25. Gonzalez, D.L., Hirasaki, G.J., Creek, J., Chapman, W.G., Modeling of Asphaltene Precipitation Due to Changes in Composition Using the Perturbed Chain Statistical Associating Fluid Theory Equation of State. Energy Fuels 2007. 21: 1231-1242.

26. Shirani, B., Nikazar, M., Mousavi-Dehghani, S.A., Prediction of asphaltene phase behavior in live oil with CPA equation of state. Fuel 2012. 97: 89-96.

27. Arya, A., von Solms, N., Kontogeorgis, G.M., Determination of asphaltene onset conditions using the cubic plus association equation of state. Fluid Phase Equilibria 2015. 400: 8-19.

28. Arya, A., Liang, X., von Solms, N., Kontogeorgis, G.M., Modeling of asphaltene precipitation from crude oil with the Cubic Plus Association equation of state. Energy Fuels 2017. 31(2): 2063-2075.

29. Li, Z., Firoozabadi, A., Cubic-Plus-Association Equation of State for Asphaltene Precipitation in Live Oils. Energy Fuels 2009. 24: 2956-2963. 
30. Arya, A., Liang, X., von Solms, N., Kontogeorgis, G.M., Prediction of Gas Injection Effect on Asphaltene Precipitation Onset Using the Cubic and Cubic-Plus-Association Equations of State. Energy Fuels 2017. 31(3): 3313-3328.

31. Li, Z., Firoozabadi, A., Modeling Asphaltene Precipitation by n-Alkanes from Heavy Oils and Bitumens Using Cubic-Plus-Association Equation of State. Energy Fuels 2010. 24: 11061113.

32. Saber, N., Shaw, J.M., On the Phase Behavior of Athabasca Vacuum Residue + n-Decane. Fluid Phase Equilibria 2011. 302: 254-259.

33. Mancilla-Polanco, A., Johnston, K., Richardson, W.D.L., Schoeggl, F.F., Zhang, Y., Yarranton, H.W., Taylor, S.D., The phase behavior of heavy oil and propane mixtures. SJ0718-0002, SPE J. accepted July 2018.

34. Akbarzadeh, K., Alboudwarej, H., Svrcek, W., Yarranton, H.W., A generalized regular solution model for asphaltene precipitation from n-alkane diluted heavy oils and bitumens. Fluid Phase Equilibria 2005. 232: 159-170.

35. Michelsen, M. L., Hendriks, E. M. Physical Properties from Association Models. Fluid Phase Equilib. 2001, 180, 165-174.

36. Lee, B., Kesler, M.G., A generalized thermodynamic correlation based on three-parameter corresponding states. AIChE J. 1975. 21(3): 510-527.

37. Katz, D.L., Firoozabadi, A., Predicting phase behavior of condensate/crude-oil systems using methane interaction coefficients. Journal of Petroleum Technology 1978. 30(11): 1649-1655.

38. Barrera, D.M., Ortiz, D.P., Yarranton, H.W., Molecular Weight and Density Distributions of Asphaltenes from Crude Oils. Energy Fuels 2013. 27(5): 2474-2487.

39. Johnston, K.A., Satyro, M.A., Taylor, S.D., Yarranton, H.W., Can a Cubic Equation of State Model Bitumen-Solvent Phase Behavior? Energy Fuels 2017. 31(8): 7967-7981. 


\section{Appendix A: Association Energy Parameter Tables}

Table A1. First half of the matrix of self-association and cross-association energy parameters for the CPA-C5 characterization. Elliot refers to the Elliot mixing rule (Eq. 10).

\begin{tabular}{|c|c|c|c|c|c|c|c|c|c|c|c|c|c|c|c|c|c|c|c|c|}
\hline & Mal 1 & Mal 2 & Mal 3 & Mal 4 & Mal 5 & Mal 6 & Mal 7 & Mal 8 & Mal 9 & Mal 10 & Asph 1 & Asph 2 & Asph 3 & Asph 4 & Asph 5 & Asph 6 & Pentane & Hexane & Heptane & Octane \\
\hline Mal 1 & 0 & 0 & 0 & 0 & 0 & 0 & 0 & 0 & 0 & 0 & 3923 & 3923 & 3923 & 3923 & 3923 & 3923 & 0 & 0 & & \\
\hline Mal 2 & 0 & 0 & 0 & 0 & 0 & 0 & 0 & 0 & 0 & 0 & 3923 & 3923 & 3923 & 3923 & 3923 & 3923 & 0 & 0 & 0 & \\
\hline Mal 3 & 0 & 0 & 0 & o & 0 & 0 & 0 & 0 & 0 & 0 & 3923 & 3923 & 3923 & 3923 & 3923 & 3923 & 0 & 0 & 0 & \\
\hline Mal 4 & 0 & 0 & 0 & 0 & 0 & 0 & 0 & 0 & 0 & 0 & 3923 & 3923 & 3923 & 3923 & 3923 & 3923 & 0 & 0 & 0 & \\
\hline nal 5 & 0 & 0 & 0 & 0 & 0 & 0 & 0 & 0 & 0 & 0 & 3923 & 3923 & 3923 & 3923 & 3923 & 923 & 0 & 0 & 0 & \\
\hline Mal 6 & 0 & 0 & 0 & 0 & 0 & 0 & 0 & 0 & 0 & 0 & 3923 & 3923 & 3923 & 3923 & 3923 & 923 & 0 & 0 & 0 & \\
\hline Mal 7 & 0 & 0 & 0 & 0 & 0 & 0 & 0 & 0 & 0 & 0 & 3923 & 3923 & 3923 & 3923 & 3923 & 3923 & 0 & 0 & 0 & \\
\hline Mal 8 & 0 & 0 & 0 & 0 & 0 & 0 & 0 & 0 & 0 & 0 & 923 & 3923 & 3 & 923 & 3923 & 3 & 0 & 0 & 0 & \\
\hline Mal 9 & 0 & 0 & 0 & 0 & 0 & 0 & 0 & 0 & ( & 0 & 3923 & 3923 & 3923 & 3923 & 3923 & 3923 & 0 & 0 & 0 & \\
\hline Mal 10 & 0 & 0 & 0 & of & 0 & 0 & 0 & 0 & 0 & 0 & 3923 & 3923 & 3923 & 3923 & 3923 & 3923 & 0 & 0 & 0 & \\
\hline Asph & & & 23 & 23 & 23 & 23 & 23 & 23 & 223 & 23 & 6840 & Elliot & Elliot & Elliot & Elliot & Elliot & 2580 & 5500 & 3500 & 3500 \\
\hline Asph 2 & 23 & 23 & 23 & 23 & 3923 & 923 & 3923 & 3923 & 3923 & 3923 & Elliot & 6900 & Elliot & Elliot & Elliot & Elliot & 2580 & 3050 & 3200 & 3250 \\
\hline Asph 3 & & & 23 & 23 & 3923 & 3923 & 3923 & 3923 & 3923 & 3923 & Elliot & Elliot & 6960 & Elliot & Elliot & Elliot & 2580 & 2600 & 2900 & 3000 \\
\hline \begin{tabular}{|l|} 
Asph 4 \\
\end{tabular} & 23 & 3 & 3923 & 23 & 3923 & 3923 & 3923 & 3923 & 3923 & 3923 & Elliot & Elliot & Elliot & 7020 & Elliot & Elliot & 2580 & 2580 & 2580 & 2750 \\
\hline Asph 5 & 3923 & 3923 & 3923 & 923 & 3923 & 3923 & 3923 & 3923 & 3923 & 3923 & Elliot & Elliot & Elliot & Elliot & 7080 & Elliot & 2580 & 2580 & 2580 & 2580 \\
\hline Asph 6 & 3923 & 3923 & 3923 & 3923 & 3923 & 3923 & 3923 & 3923 & 3923 & 3923 & Elliot & Elliot & Elliot & Elliot & Elliot & 7140 & 2580 & 2580 & 2580 & 2580 \\
\hline Pentane & 0 & 0 & 0 & 0 & 0 & 0 & 0 & 0 & 0 & 0 & 2580 & 2580 & 2580 & 2580 & 2580 & 2580 & 0 & 0 & 0 & \\
\hline Hexan & 0 & 0 & 0 & 0 & 0 & 0 & 0 & 0 & 0 & 0 & 3250 & 3015 & 2780 & 2580 & 2580 & 2580 & 0 & 0 & 0 & \\
\hline Hept & 0 & 0 & of & of & 0 & 0 & 0 & 0 & 0 & 0 & 3250 & 3115 & 980 & 2845 & 10 & 580 & 0 & 0 & 0 & \\
\hline Octana & 0 & 0 & 0 & 0 & 0 & 0 & 0 & 0 & 0 & 0 & 3250 & 3135 & 3020 & 2905 & 2790 & 2675 & 0 & 0 & 0 & \\
\hline
\end{tabular}


Table A2. The matrix of self-association and cross-association energy parameters for CPA-C3 characterization. Elliot refers to the Elliot mixing rule (Eq. 10).

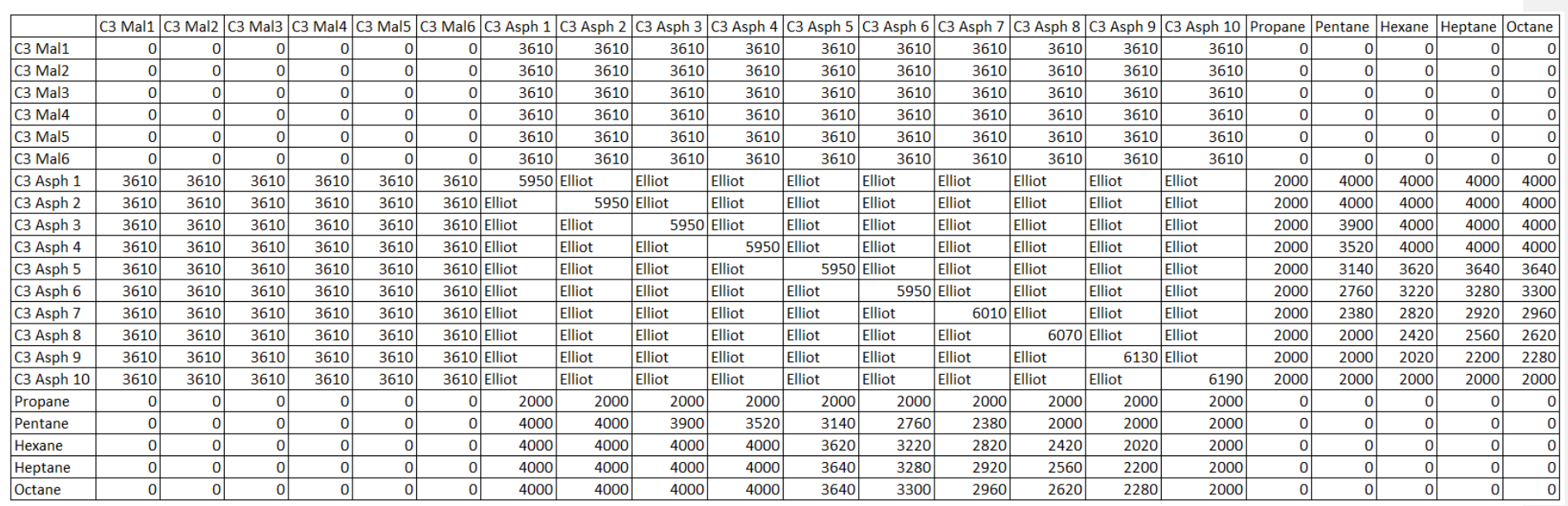

